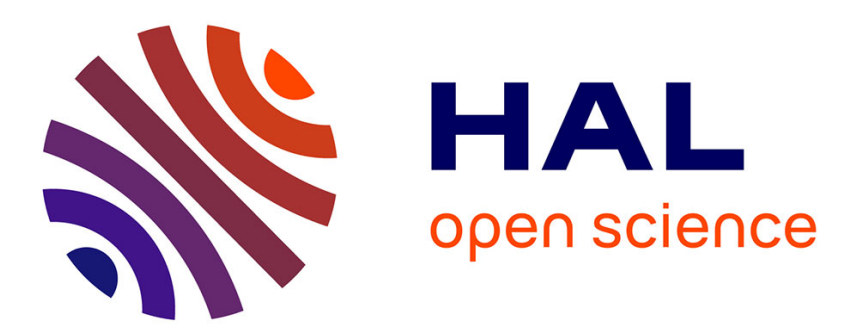

\title{
Mass-independent fractionation of titanium isotopes and its cosmochemical implications
}

\author{
François Robert, Romain Tartese, Guillaume Lombardi, Peter Reinhardt, \\ Mathieu Roskosz, Béatrice Doisneau, Zhengbin Deng, Marc Chaussidon
}

\section{> To cite this version:}

François Robert, Romain Tartese, Guillaume Lombardi, Peter Reinhardt, Mathieu Roskosz, et al.. Mass-independent fractionation of titanium isotopes and its cosmochemical implications. Nature Astronomy, 2020, 10.1038/s41550-020-1043-1 . insu-02898345

\section{HAL Id: insu-02898345 \\ https://hal-insu.archives-ouvertes.fr/insu-02898345}

Submitted on 4 Dec 2020

HAL is a multi-disciplinary open access archive for the deposit and dissemination of scientific research documents, whether they are published or not. The documents may come from teaching and research institutions in France or abroad, or from public or private research centers.
L'archive ouverte pluridisciplinaire HAL, est destinée au dépôt et à la diffusion de documents scientifiques de niveau recherche, publiés ou non, émanant des établissements d'enseignement et de recherche français ou étrangers, des laboratoires publics ou privés. 


\section{Mass-Independent Fractionation of Titanium Isotopes and its Cosmochemical Implications}

François Robert ${ }^{*}$, Romain Tartèse ${ }^{2}$, Guillaume Lombardi ${ }^{3}$, Peter Reinhardt ${ }^{4}$, Mathieu Roskosz ${ }^{1}$, Béatrice Doisneau ${ }^{1}$, Zhengbin Deng 5 , Marc Chaussidon ${ }^{5}$

\section{Affiliations:}

${ }^{1}$ Muséum National d'Histoire Naturelle, Institut de Minéralogie, Physique des Matériaux et Cosmochimie, CNRS UMR 7590, 61 rue Buffon, 75005 Paris, France.

2Department of Earth and Environmental Sciences, The University of Manchester, Oxford Road, Manchester M13 9PL, UK.

32aboratoire des Laboratoire des Sciences des Procédés et des Matériaux, CNRS, Université Paris 13, Sorbonne Paris Cité, 93430 Villetaneuse, France

${ }^{4}$ Laboratoire de Chimie Théorique, Sorbonne Université et CNRS UMR 7616, 4 place Jussieu, 75252 Paris Cedex 05, France.

5Université de Paris, Institut de Physique du Globe de Paris, CNRS, F-75005 Paris, France. 
Isotopes of heavy elements are produced in various amounts by nuclear processes in stars $^{1,2}$. Consequently, the presence of isotopic anomalies in the Solar System is considered to reflect the presence of presolar grains condensed in previous generations of stars $^{3}$. For oxygen however, the major rock-forming element, it has been shown that physico-chemical reactions applicable to the presolar cloud or the protoplanetary disk were a possible source of isotopic variations due to mass-independent isotopic fractionation (MIF) ${ }^{4,5}$. Here we show that MIF effects are not restricted to oxygen but can also be produced for titanium. Titanium-rich grains experimentally condensed from a $\mathrm{TiCl}_{4(\mathrm{~g})}-\mathrm{C}_{5} \mathrm{H}_{12(\mathrm{~g})}$ plasma exhibit $\mathrm{MIF}$ effects from $-30 \%$ to $+120 \%$ for all $\mathrm{Ti}$ isotopic ratios. These large titanium isotopic variations follow the model developed for oxygen $M^{6}{ }^{6}$ and mimic the Ti isotopic anomalies observed in some presolar grains. This effect is ascribed to the reactions between indistinguishable isotopes ${ }^{6}$. It could contribute to the complexity of isotopic anomalies observed in Solar System materials ${ }^{1,7-14}$.

Oxygen isotope systematics is often utilized as a typical example of mass-dependent (MDF) and mass-independent (MIF) isotopic fractionations. In planetary materials, when abundances of the three oxygen isotopes ${ }^{16,17,18} \mathrm{O}$ follow a MDF process they define-the "slope 0.52 " relationship $\delta^{17} \mathrm{O} \sim 0.52 \times \delta^{18} \mathrm{O}\left(\delta^{m} \mathrm{O}\right.$ in \%o given by $\left[\left(\mathrm{R}_{\text {sple }} / \mathrm{R}_{\text {std }}\right)-1\right] \times 10^{3}$, with $\mathrm{R}=$ ${ }^{m} \mathrm{O} / 16 \mathrm{O}$; sple and std standing for sample and standard, respectively, and $m$ for the masses 17 or 18) ${ }^{15}$. However, in Calcium-Aluminum Rich Inclusions (CAIs) and in insoluble organic matter of the carbonaceous meteorites, $\mathrm{O}$ isotope variations are characterized by a slope $\sim 1$ in the $\delta^{17} \mathrm{O}$ versus $\delta^{18} \mathrm{O}$ diagram ${ }^{3,16}$. No consensus has yet been reached on the nuclear or chemical origin of the "slope 1 " line ${ }^{17}$. Two types of physico-chemical processes have been proposed to account for the production of MIF in the protosolar nebula (PSN) or in the molecular cloud predating the formation of the PSN: either self-shielding of CO gas under UV irradiation ${ }^{18}$ or a selection of ${ }^{16} \mathrm{O}$ by chemical reactions similar to those involved in the synthesis of ozone ${ }^{4,5}$. In addition, CAIs contain numerous MIF (reported as "isotopic anomalies" to distinguish their nuclear origins) for other chemical elements ${ }^{1,2}$. These anomalies are more prominent in presolar grains containing stellar nucleosynthetic signatures $^{7-14}$.

The presence of these presolar grains in the PSN is considered to be the source of all the isotopic anomalies observed in meteoritic and planetary material. However, the co-existence of oxygen MIF and isotopic anomalies in CAIs questions the possibility that some isotopic anomalies, in presolar or solar objects, could have a MIF origin. No chemical reaction has ever been shown to be able to generate MIF for heavy elements such as $\mathrm{Ti}, \mathrm{Mo}, \mathrm{Cr}$, or $\mathrm{Ca}$. Here we investigate experimentally whether MIF could be produced for Ti during gas phase reactions analogous in their mechanism to the formation of ozone.

At their high temperatures of formation, presolar grains or CAIs and their precursors, are under their gaseous state ${ }^{19}$. Because of the difficulty to conduct experimental photochemical 
reactions in these conditions, we have chosen to study the reduction of gaseous titanium chloride $\mathrm{TiCl}_{4}$ during its condensation on grains after its dissociation in a hyperfrequency (HF) plasma. In this respect, our aim was not to reproduce the canonical chemical and physical conditions of stellar envelopes or of the PSN, but to transpose to a Ti-bearing gaseous environment the physico-chemical conditions derived from the interpretation accounting for oxygen MIF in ozone ${ }^{6,20}$.

The experimental apparatus has been described previously ${ }^{21}$. The vapor pressure of $\mathrm{TiCl}_{4}: \mathrm{C}_{5} \mathrm{H}_{12}$ (1:2) liquid solution (see Methods 1 for the role of $\mathrm{C}_{5} \mathrm{H}_{12}$ ) was leaked in a $\mathrm{N}_{2}$ flow gas at $\approx 1$ mbar $\left(\left[\mathrm{TiCl}_{4}-\mathrm{C}_{5} \mathrm{H}_{12}\right]: \mathrm{N}_{2} \approx 1: 1\right)$. The plasma was maintained stable by dynamic pumping of a cylinder glass tube $(\emptyset=1 \mathrm{~cm}, l=10 \mathrm{~cm})$ subjected to a HF discharge at 2450 $\mathrm{MHz}$. Ti-bearing films of organic matter (OM films) were observed to deposit either on the glass walls or on the silicon wafers (as 10-100 nm thick films; see Methods 2 and Supplementary Figs. 1 and 2) located before, right at the center, and after the discharge (with corresponding samples referred to as Upstream, Central, and Downstream). On Downstream wafers, organic Ti-Cl rich grains up to $2 \mu \mathrm{m}$ in size were found to sit on top of the OM films. While OM films form by condensation on the cold glass walls $\left(\approx 60{ }^{\circ} \mathrm{C}\right)$, these spherical organic Ti-rich grains are considered to form by homogeneous condensation in the gas phase. A discussion on the chemical composition of these experimental products can be found in Methods 2. The Ti isotopic compositions were measured by NanoSIMS. Analytical procedures are reported in Methods 2 and 3 and Supplementary Information 2. Results are reported in Table 1 in Methods and in Supplementary Information 3 for 3 different experiments (FR2, FR4 and FR5).

Overall, positive and negative $\mathrm{Ti}$ isotopic anomalies are observed at all masses in all samples except in FR2 Upstream wafers. A few illustrative Ti isotopic patterns are reported in Figs. 1a-d, where $\delta^{m} \mathrm{Ti}$ are plotted versus the isotopic mass number $m$. In these diagrams, all types of known MDF should be limited to a few \%o and should strictly define linear correlations. During experiment FR2 (Fig.1a), no grain was formed and the OM films deposited on the wafer downstream of the plasma show limited isotopic fractionation. In upstream regions (Fig. 1b; FR5), MDF of Ti isotopes in OM films exists, likely reflecting the process of condensation $\left(\delta^{m-1} \mathrm{Ti}>\delta^{m} \mathrm{Ti}\right)$. However, in a few analytical spots, MIF appears in isotopic patterns. On a central wafer (Fig.1c; FR4) both positive and negative $\delta^{m} \mathrm{Ti}$ values are observed with clear departures from a pure MDF pattern, with one analyzed area having negative $\delta^{m} \mathrm{Ti}$ values at all masses $(46,47,49,50 \mathrm{Ti})$. In downstream regions (Fig. 1d; FR5), the spherical Ti-rich grains are characterized by large Ti isotope variability, with both positive and negative anomalies, at the micrometer scale. A high-resolution analysis of one of these $2 \mu \mathrm{m}$ size Ti-rich grains is shown in Fig. $2 \mathrm{~b}$ and Table 1 in Methods. Numerical analysis of the ion image shows that negative $\delta^{m} \mathrm{Ti}$ values are associated with the surface of the grain while positive $\delta^{m} \mathrm{Ti}$ values are concentrated in the core. The $\delta^{m} \mathrm{Ti}$ values increase from $c a$. $-200 \%$ 
to $c a .+1200 \%$ while the Ti concentration decreases from the rim to the core (Fig.2b). At the image bulk scale, the MIF are much weaker (Table 1 in Methods), indicating, based on mass balance, that $\mathrm{Ti}$ condensation was nearly total during this experiment. This radial change in $\delta^{m}$ Ti may reflect two chemical regimes of condensation.

All the measured isotopic variations are reported as $\delta^{50} \mathrm{Ti} v s$. $\delta^{46} \mathrm{Ti}$ in Fig. $2 \mathrm{c}$. In this Figure, the Ti isotope variations for the different areas of the grain investigated in detail are noted from 1 to 6 , and refer to the data reported in Table 1 Methods. The theoretical MDF (slope $=-1.16$ ) and MIF (slope $=+1.04$ ) slopes are shown as reference lines calculated by the prescriptions proposed by Robert 22 (see Methods 4). A blow-up of the Fig.2 (cf. Supplementary Fig. 4) shows that for small variations $\left( \pm 40 \%\right.$ o), $\delta^{m} \mathrm{Ti}$ variations roughly define a mass-dependent relationship. The consistency between observed MIF and theoretical predictions is also clear in a Fig. 3 showing the $\delta^{m}$ Ti variations for masses 46, 47, 49, and 50.

As suggested by Marcus ${ }^{23}$, the surface of a growing grain acts as a concentrator and is characterized by entropic effects higher by several orders of magnitude relative to the gas phase, thus increasing the rate of isotopic exchange at the surface of grains. In the present experiment, we propose that, at the surface of the grain, the metastable molecules $\left[\mathrm{Cl}_{2}{ }^{\mathrm{i}} \mathrm{Ti} \ldots\right.$ $\left.\mathrm{jTiCl}_{2}\right]^{*}$, formed from reactions with Ti resulting from the dissociation of $\mathrm{TiCl}_{4}$ in the plasma, are deactivated by the reaction with the organic carbon radicals $\left(\mathrm{CH}_{2}{ }^{\circ}\right)$ produced by the molecular dissociation of pentane:

$$
\begin{aligned}
& { }^{\mathrm{i}} \mathrm{TiCl}_{4}+\mathrm{j} \mathrm{Ti} \rightarrow\left[\mathrm{Cl}_{2}{ }_{2}^{\mathrm{i}} \mathrm{Ti}_{\ldots} . . \mathrm{TiCl}_{2}\right]^{*} \rightarrow{ }^{\mathrm{i}} \mathrm{TiCl}_{4}+{ }^{\mathrm{i}} \mathrm{Ti} \\
& {\left[\mathrm{Cl}_{2}{ }^{\mathrm{i}} \mathrm{Ti}_{2} . . \mathrm{TiCl}_{2}\right]^{*}+\mathrm{CH}_{2}{ }^{\bullet} \rightarrow{ }^{\mathrm{i}, \mathrm{j}} \mathrm{Ti}-\mathrm{CH}_{\mathrm{x}}+\ldots}
\end{aligned}
$$

where $i$ and $j$ stand for any isotope mass number from 46 to 50 .

Two types of interpretations of this MIF effect for $\mathrm{O}$ isotopes in ozone have been proposed (see Supplementary Information 5). They involve either (i) the molecular symmetry of the metastable molecule ${ }^{23-25}$ or (ii) the higher degree of symmetry of scattering cross sections describing the encounter between two indistinguishable isotopes (i.e. $i=j$ ) compared to those between distinguishable isotopes ${ }^{6}$ (i.e. $i \neq j$ ). Both effects lead to the same numerical formalism for MIF patterns. Neglecting as a first approximation the mass-dependent terms ( $\alpha$ 's $=1$ in Methods 4 - equation 5), and taking into account all the 25 reactions between the five isotopes of $\mathrm{Ti}$, the MIF model yields a slope of 1.04 in the $\delta^{50} \mathrm{Ti} v s$. $\delta^{46} \mathrm{Ti}$ diagram (Fig. 2c). The calculated pattern reported in Figure 3 uses a MIF factor $\eta=4$ that yields $\delta^{m} \mathrm{Ti}$ around $1200 \%$ for the four Ti isotope ratios. This $\eta$ value is numerically compatible with the second interpretation (ii) (cf. Supplementary Fig.5). The MDF terms, ignored in this firstorder calculation, likely play a significant role in the domain of a few per mil variations, yielding more complex patterns as those experimentally observed in the $-50 /+50 \%$ range. 
The present demonstration that large MIF effects can be experimentally produced for $\mathrm{Ti}$ isotopes has, potentially, profound implications for cosmochemistry. The largest known Ti isotope anomalies are found in presolar $\mathrm{SiC}$ grains isolated from chondritic meteorites ${ }^{7-9,13}$. Their Ti isotope compositions are compared in Fig.4 with the present experimental results (see also Supplementary Fig.6a to 6c for comparison with other presolar grains ${ }^{7-14}$ and with FUN CAIs (FUNs exhibit both MDF and MIF effects). Although TiC is a possible chemical product of reaction (2) and is expected to form in carbon-rich environments (such as envelopes of carbon-rich stars), it has not been possible to identify in the present OM films or grains, the chemical speciation of $\mathrm{Ti}$ (metallic, organic hetero-element, $\mathrm{TiCl}_{\mathrm{x}}, \mathrm{TiC}$ ?).

Note in addition that, in our theoretical treatment of MIF, carbon plays no role in the production (or not) of MIF. Despite the fact that the highest experimental $\delta^{m} \mathrm{Ti}$ values $(+1200 \%$ ), have not been observed for SiC (Fig.4), the similarities between the Ti isotope compositions of presolar $\mathrm{SiC}$ and of some of the present experimental condensates (Fig.4) opens the possibility that presolar grains condensed in stellar atmospheres contain an undetermined contribution of MIF in their Ti isotopic composition. However, this potential contribution to the Ti isotopic variability is at present difficult to identify since, for instance, $s$-process $\mathrm{Ti}$ is expected to be enriched in all $\mathrm{Ti}$ isotopes (and especially ${ }^{50} \mathrm{Ti}$ relative to ${ }^{48} \mathrm{Ti}^{10}$ ) a feature quite similar to some of the predicted MIF effects. In this respect, the MIF effect is, at first order, an abundance-dependent isotopic fractionation.

Non-FUN CAIs and bulk chondrites show much smaller Ti isotope anomalies than presolar $\mathrm{SiC}$, with $\delta^{\mathrm{m}} \mathrm{Ti}$ in the tenth of \%o range. Their Ti isotope patterns include deficit and excess of ${ }^{48} \mathrm{Ti}$ and a correlation between ${ }^{46} \mathrm{Ti}$ and ${ }^{50} \mathrm{Ti}$ excesses ${ }^{l}$. These patterns are not observed in the present experiments, but because our experimental results have uncertainties of $c a . \pm 6 \%$, it is difficult to make a significant comparison. The fact that, for small $\mathrm{Ti}$ isotopic variations, the MDF terms become commensurable with $\eta$, may account theoretically (cf. MIF model in Methods) for the discrepancy between non-FUN CAIs, bulk chondrites and the present experiments. This point remains an experimental and analytical open issue.

Thus, it is not possible yet to transpose the present experiments to conditions relevant to high-temperature condensation in the PSN or stellar atmospheres. To do so one could consider for instance that the $\mathrm{Ti} / \mathrm{TiCl}_{2} / \mathrm{TiCl}_{4}$ system investigated here could be an analog of the $\mathrm{Ti} / \mathrm{TiO} /$ $\mathrm{TiO}_{2}$ system relevant to the formation of Ti-bearing condensates at high temperature. Reactions between $\mathrm{TiO}$ and $\mathrm{TiO}_{2}$ on grains may form the metastable molecule $\left[\mathrm{OTiTiO}_{2}\right.$ ]* then stabilized as $\mathrm{Ti}_{2} \mathrm{O}_{3}$, i.e. as one of the possible Ti oxides precursors (with other Ti-bearing refractory phases such as titanates ${ }^{19}$ of CAIs). This raises the question whether such reactions during condensation of grains could also produce various MIF effects for oxygen isotopes. However, the fact that large MIF effects can be experimentally produced for a refractory element like Ti opens a new field of investigations for isotope effects for other elements in order to distinguish between potential MIF effects produced by chemical reactions and 
nuclear anomalies. This will necessitate to investigate chemical reactions in plasmas and their possible extensions to the PSN. 


\section{REFERENCES}

1. Dauphas, N. \& Schauble, E. A. Mass fractionation laws, mass-independent effects, and isotopic anomalies. Ann. Rev. Earth Planet. Sci. 44, 709-783 (2016).

2. Birck, J. L. An overview of isotopic anomalies in extraterrestrial materials and their nucleosynthetic heritage. Reviews in Mineralogy \& Geochemistry, 55, pp. 25-64, (2004).

3. Clayton, R. N., Grossman, L. \& Mayeda, T. K. A component of primitive nuclear composition in carbonaceous meteorites, Science 182, 485-488 (1973).

4. Thiemens, M. H. \& Heidenreich, J. E. The mass-independent fractionation of oxygen - a novel isotope effect and its possible cosmochemical implications. Science 219, 1073-1075 (1983).

5. Thiemens, M. H. Introduction to chemistry and applications in nature of mass indepedendent isotope effects special feature. PNAS 110, 44, 17631-17637 (2013).

6. Reinhardt, P. \& Robert, F. On the mass independent isotopic fractionation in ozone. $J$. Chem. Phys. 513, 287-294 (2018).

7. Zinner, E. K. et al. NanoSIMS isotopic analysis of small presolar grains: Search for $\mathrm{Si}_{3} \mathrm{~N}_{4}$ grains from $\mathrm{AGB}$ stars and $\mathrm{Al}$ and $\mathrm{Ti}$ isotopic compositions of rare presolar $\mathrm{SiC}$ grains. Geochim. Cosmochim. Acta. 71, 19,_4786-4813 (2007).

8. Ireland, T. R., Zinner, E. K. \& Amari S. Isotopically anomalous Ti in presolar SiC from the Murchison meteorite. Astrophys. J. 376, L53-L56 (1991).

9. Huss, G. R. \& Smith, J. B. Titanium isotopic compositions of well-characterized silicon carbide grains from Orgueil (CI): Implications for s-process nucleosynthesis. Meteor. Planet. Sci. 42, 1055-1075 (2007).

10. Leya, I., Schönbächler, M., Wiechert, U., Krähenbühl, U. \& Halliday A. Titanium isotopes and the radial heterogeneity of the solar system. Earth. Planet. Sci. Lett. 266, 233-244 (2008).

11. Trinquier, A., Elliott, T., Ulfbeck, D., Coath, C., Krot, A .N. \& Bizzarro, M. Origin of nucleosynthetic isotope heterogeneity in the solar protoplanetary disk. Science 324, 374376 (2009).

12. Davis, A. M., Zhang, J., Greber, N. D., Jingya Hu, J., Tissot, F. L. H. \& Dauphas N. Titanium isotopes and rare earth patterns in CAIs: evidence for thermal processing and gas-dust decoupling in the protoplanetary disk. Geochim. Cosmochim. Acta 221, 275-295 (2018).

13. Gyngard, F., Amari, S., Zinner, E. K. \& Marhas K. K. Correlated silicon and titanium isotopic compositions of presolar $\mathrm{SiC}$ grains from the Murchison CM2 chondrite. Geochim. Cosmochim. Acta 221, 145-161 (2018).

14. Nguyen, A. N., Nittler, L. R., Alexander C. M. O’D. \& Hoppe P. Titanium isotopic compositions of rare presolar $\mathrm{SiC}$ grain types from the Murchison meteorite. Geochim. Cosmochim. Acta 221, 162-181 (2018). 
15. Young, E. D., Galy, A. \& Nagahara H. Kinetic and equilibrium mass-dependent isotope fractionation laws in nature and their geochemical and cosmochemical significance. Geochim. Cosmochim. Acta 66, 1095-1104 (2002).

16. Tartese R., Chaussidon M., Gurenko A., F. Delarue \& Robert F., Insights into the origin of the carbonaceous chondrite organics from their triple oxygen isotope composition. Proc. Nat. Acad. Sci. 115, 8535-8540 (2018).

17. Kööp, L., Davis, A. M., Nakashima, D., Park, C., Krot, A. N., Nagashima, K., Tenner, T. J., Heck, P. R. \& Kita N.T. A link between oxygen, calcium and titanium isotopes in ${ }^{26}$ Alpoor hibonite-rich CAIs from Murchison and implications for the heterogeneity of dust reservoirs in the solar nebula. Geochim. Cosmochim. Acta 189.70-95 (2016).

18. Yurimoto, H. \& Kuramoto, K. Molecular cloud origin for the oxygen isotope heterogeneity in the solar system. Science 305,1763-1766 (2004).

19. Lodders, K. Titanium and Vanadium chemistry in low-mass Dwarf stars. Astrophys. J. 577, 974-985 (2002).

20. Reinhardt, P. \& Robert, F. Mass independent isotope fractionation in ozone. Earth Planet. Sci. Lett. 368, 195-203 (2013).

21. Robert, F., Derenne, S., Lombardi, G., Hassouni, K., Michau, A., Reinhardt, P., Duhamel, R., Gonzalez, A. \& Biron, K. Hydrogen isotope fractionation in methane plasma. Proc. Nat. Acad. Sci. 114, 870-874, (2017).

22. Robert, F. The common property of isotopic anomalies in meteorites. Astron \& Astrophys. 415, 1167-1176 (2004).

23. Marcus, R. A. Mass-independent isotope effect in the earliest processed solids in the solar system: A possible chemical mechanism. J. Chem. Phys. 121, 8201-8211 (2004).

24. Gao, Y. Q. \& Marcus, R. A. On the theory of the strange and unconventional isotopic effects in ozone formation. J. Chem. Phys. 116, 137 (2002).

25. Babikov, D. Recombination reactions as a possible mechanism of mass-independent fractionation of sulfur isotopes in the Archean atmosphere of Earth. Proc. Nat. Acad. Sci. 114, 3062-3067 (2017).

26. Murphy, A. B. Formation of titanium nanoparticles from a titanium tetrachloride plasma. J. Phys. D: Appl. Phys. 37, 2841 (2004).

27. Biron, K., Derenne, S., Robert, F., \& Rouzaud, J. N. Toward an experimental synthesis of the chondritic insoluble organic matter. Meteor. Planet. Sci.50, 1408-1422 (2015).

28. Janssen, C., Guenther, J., Mauersberger, K. \& Krankowsky, D. Kinetic origin of the ozone isotope effect: a critical analysis of enrichments and rate coefficients. Phys. Chem. Chem. Phys. 3, 4718-4721 (2001).

29. Schinke, R., \& Fleurat-Lessard, P. The effect of zero-point energy differences on the isotope dependence of the formation of ozone : a classical trajectory study. J. Chem. Phys., 122, 094317 (2005). 
30. Ivanov, M. V. \& Babikov, D. On molecular origin of mass-independent fractionation of oxygen isotopes in the ozone forming recombination reaction. Proc. Nat. Acad. Sci. 110, 17708-17713 (2013).

Correspondence and requests for materials should be addressed to F. Robert (francois.robert@mnhn.fr)

Acknowledgments: Funding: F.R. acknowledges support (Overheads) of ERC Advanced Grant PaleoNanoLife (PI: F. Robert; 161764). R.T. acknowledges support from the UK Science and Technology Facilities Council (ST/P005225/1). At The University of Manchester, the NanoSIMS was funded by UK Research Partnership Investment Funding (UKRPIF) Manchester RPIF Round 2, and installation of a Hyperion RF plasma ion source supported by the Henry Royce Institute for Advanced Materials, funded through EPSRC grants EP/ R00661X/1, EP/P025021/1 and EP/P025498/1. MC acknowledges support of ANR Cradle (ANR-15-CE31-0004-01).

Author contributions: F.R. designed the project and provided samples for this study. R.T. performed and analyzed the NanoSIMS data. F.R., R.T., Z.D. M.C. interpreted the results in the field of Cosmochemistry and wrote the paper. G.L. Interpreted the results in the field of plasma physics. B.D. and M.R. obtained and interpreted the microscopic images. P.R.

participated to the interpretation of the Ti-MIF effects in the field of theoretical physics.

Competing interests: Authors declare no competing interests. 
Data and materials availability: All data is available in the main text or the supplementary materials. 


\section{Figure Captions}

Fig. 1: Titanium isotope ratios $(m \mathrm{Ti} / 48 \mathrm{Ti})$ in $\mathrm{OM}$ deposited from a $\mathrm{TiCl}_{4} / \mathrm{C}_{5} \mathrm{H}_{12}$ plasma. Results are given using the $\delta^{m} \mathrm{Ti}(\%)$ notation, with $m$ standing for masses $46,47,48,49$, and 50 . Individual $\delta^{m} \mathrm{Ti}(\%)$ values obtained for the same analysis are connected by solid or dashed lines. The positions of the samples (Upstream, Downstream and Central) are defined relative to the flow of the carrier gas $\mathrm{N}_{2}$ and the location of the plasma discharge (e.g., central refers to the HF position). Figure $1 \mathrm{~d}$ displays results of a numerical image analysis of a Ti-rich grain area $(\approx 5 \times 5 \mu \mathrm{m})$.

Fig. 2: Titanium isotopic variations in carbonaceous matter deposited from a $\mathrm{TiCl}_{4} / \mathrm{C}_{5} \mathrm{H}_{12}$

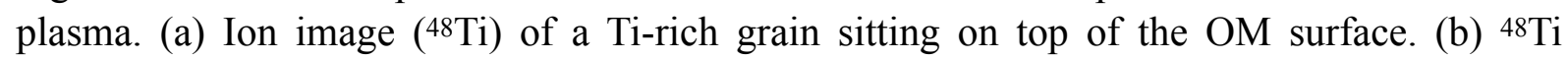
concentration profile, showing that $\mathrm{Ti}$ is systematically concentrated at the surface of the grains. The $\delta^{50} \mathrm{Ti}$ values of the different concentration domains are shown and labelled 1 to 6 . (c) The Ti isotope compositions of all measured samples reported as $\delta^{50} \mathrm{Ti}$ versus $\delta^{46} \mathrm{Ti}$. The theoretical mass-dependent (MDF) and mass-independent (MIF) fractionation slopes are reported as reference dashed lines. The zoning of the grain noted 1 to 6 , corresponds to the analyses reported in (b) and in Table 1 in Methods. A blowup shows MDF Ti isotope variations (Supplementary Fig.4) at smaller scales. Error bars combine the reproducibility on the standard and the counting statistic uncertainties

Fig. 3: Titanium isotopic compositions expressed as $\delta^{m} \mathrm{Ti} v$ s. masses $m=46,47,48,49$, and 50. The positive and negative $\delta^{m} \mathrm{Ti}$ values (in black and dashed lines) correspond to the core (dots) and to the very surface (diamonds) of the grain shown in Fig.2a, respectively. Error bars combine the reproducibility on the standard and the counting statistic uncertainties. The numerical simulation of a MIF effect ${ }^{22}$ is shown as a solid line (open diamonds).

Fig. 4: The isotopic compositions of titanium in presolar grains isolated from the Murchison, Orgueil and Indarch chondrite meteorites ${ }^{7-9,13}$ is compared with the present experimental data (yellow circles). Error bars on experimental data combine the reproducibility on the standard and the counting statistic uncertainties. 


\section{Methods}

\section{Plasma Experiments.}

The formation of organic matter films and Ti-bearing organic grains was achieved using a hyperfrequency (HF) excitation able to ionize a gas, which reaches the so-called "plasma state". The initial mixture was composed of different molecular species, i.e. (i) nitrogen $\left(\mathrm{N}_{2}\right)$ as a buffer gas and (ii) titanium tetrachloride $\left(\mathrm{TiCl}_{4}\right)$ solubilized in pentane $\left(\mathrm{C}_{5} \mathrm{H}_{12}\right)$, in a ratio $2: 1$, as product precursors. Pentane was introduced as an additional compound to trigger the reduction of the metastable molecule $\left[\mathrm{Cl}_{2} \mathrm{Ti} \ldots \mathrm{TiCl}_{2}\right]^{*}$ by the $\mathrm{CH}_{2} \cdot$ radicals resulting from the dissociation of pentane. In such a situation, a mass-independent fractionation (MIF) effect should be produced between the two channels (cf. reactions 1 and 2 in the text).

The total pressure was maintained constant around $100 \mathrm{~Pa}$. The reactor is made of a quartz tube of $10 \mathrm{~cm}$ in diameter. The plasma was generated by coupling a microwave excitation at $2450 \mathrm{MHz}$ with around $30-40 \mathrm{~W}$ of power coupled to the gas. It created a plasma of around $10 \mathrm{~cm}$ in length in which the residence time of the gas was around $1 / 5 \mathrm{~s}$ measured from the amount of liquid injected in $\mathrm{N}_{2}$ during the whole duration of the experiment (from 10 min. to 1 hour $)$. For shorter residence time $(<1 / 10 \mathrm{~s})$, the formation of grains is not observed.

This type of microwave plasma was chosen for the following advantages with respect to the aimed application: (i) a limited contamination since no electrodes are in contact with the plasma, (ii) a direct heating of the electrons, (iii) a quasi-continuous discharge with respect to ions and electrons that are not able to follow the fluctuation of the electric field on a microwave period, and (iv) a reduced flux of electrons impinging the surface, thus limiting etching of the reactor walls.

The gas temperature is in the range of $1000 \mathrm{~K}$. This high temperature favors the dissociation of the grain precursor and the reactivity of the titanium metallic clusters. These clusters are likely to be formed from two main paths, i.e. (i) homogeneous coagulation of nanometric clusters (in the plasma phase), which generally generates quasi-spherical particles around a metallic core 26 , and (ii) heterogeneous growth of films due to condensation of radicals on the cold wall of the plasma reactor.

\section{Samples.}

The condensation products are deposited on silicon wafers. They consist of organic matter ${ }^{27}$ produced by the polymerization of $\mathrm{CH}_{n}$ radicals and quasi-circular grains. Two representative samples (FR4-Central and FR5-Downstream) were studied by scanning and transmission electron microscopy (SEM and TEM). The SEM observations were carried out on a SEM-FEG instrument (ULTRA55, Zeiss) operating at $10 \mathrm{kV}$ to carefully image the thin 
layer of Ti-rich OM deposited on silicon wafers. The microstructure of deposited materials differs between these two samples. FR5-Downstream (Supplementary Fig.1a) present globular structures (referred in the text to as grains) whereas FR4-Central (Supplementary Fig.1b) appears to be more homogenous (referred to as OM). The largest isotopic anomalies were measured in sample FR5-Downstream (and are associated with the globular structures). Conversely, closer to the plasma, nanoparticles did not coalesce as droplets on the substrate, either because the temperature or the partial pressure were higher in this part of the reactor. Energy-dispersive X-ray spectroscopy (EDS) analyses could not be performed because of the small thickness of the organic deposit.

Two focused ion beam (FIB) sections were prepared to be studied by TEM. A random area of FR4-Central was selected while the FIB section of FR5-Downstream was excavated from one of the circular structure previously observed (Supplementary Fig.1a). The ultrathin sections were then extracted using a FIB Zeiss Neon40EsB (IMPMC, Paris, France). A Pt layer was deposited on the area of interest for protection during the preparation of the sections ( $3 \times 20 \mu \mathrm{m}^{2}$ and $2 \mu \mathrm{m}$ in thickness). Milling was carried out with a $\mathrm{Ga}^{+}$ion beam current of $30 \mathrm{kV}$. Thin sections were then welded on a $\mathrm{Cu}$ grid for TEM observations. A TEM JEOL 2100F (IMPMC, Paris, France) instrument operating at $200 \mathrm{kV}$ was used for these observations. Conventional bright field and STEM images were collected together with qualitative chemical maps.

In both samples, Ti was detected at the interface between the Si wafer and the Pt layer (Supplementary Fig.2). The Ti-bearing deposit appears structurally discontinuous but chemically homogeneous in terms of Ti content. It is similar for the two samples at the TEM scale. No diffraction patters of the Ti-rich material could be observed suggesting either a diffuse or a non-crystalline nature of the Ti-bearing phase. A significant amount of chloride was also detected by EDS in these layers but the stoichiometry is incompatible with $\mathrm{TiCl}_{4}$. Nitrogen could not be analyzed during the session and the hypothetical occurrence of TiN could not be confirmed. The nature of the Ti-bearing phase is therefore still uncertain so far. It could be an organic complex, a nitride, or nm-sized Ti metallic particles. The thickness of the organic deposit is of the order of $50 \mathrm{~nm}$.

Elemental $\mathrm{C}$, $\mathrm{Ti}$, and $\mathrm{Cl}$ ionic ratios for the samples measured with the NanoSIMS were compared with an industrial organic standard (Cyclopentadienyl-titanium dichloride). The ${ }^{48} \mathrm{Ti}^{+} / 12 \mathrm{C}^{+}\left(8.7 \pm 1.5 \times 10^{2}\right)$ and ${ }^{48} \mathrm{Ti}^{+} / 35 \mathrm{Cl}^{+}\left(4.1 \pm 2.1 \times 10^{2}\right)$ in the standard were globally constant (within $\pm 50 \%$ ), corresponding to $\mathrm{Ti} / \mathrm{C}$ and $\mathrm{Ti} / \mathrm{Cl}$ atomic ratios of 0.1 and 0.5 , respectively. Most samples exhibit higher ${ }^{48} \mathrm{Ti}^{+} / 35 \mathrm{Cl}^{+}$ratios between $3 \times 10^{2}$ and $2 \times 10^{4}$, indicating an efficient reduction of $\mathrm{TiCl}_{4}$ and an excess of $\mathrm{Ti}$ atoms in the $\mathrm{OM}$ films compared to the parent molecule $\mathrm{TiCl}_{4}$. The ${ }^{48} \mathrm{Ti}^{+} / 12 \mathrm{C}^{+}$ionic ratios range between $c a .10^{2}$ and $10^{5}$, reflecting the heterogeneous distribution of $\mathrm{Ti}$ in $\mathrm{OM}$ films. In organic grains, the ${ }^{48} \mathrm{Ti}^{+} / 35 \mathrm{Cl}^{+}$ 
ionic ratios decrease from the surface $\left(c a .4 \times 10^{3}\right)$ to the core $\left(3 \times 10^{2}\right)$ with no significant variation of the ${ }^{48} \mathrm{Ti}^{+} / 12 \mathrm{C}^{+}$ionic ratios $\left(\mathrm{ca} .2 \times 10^{3}\right)$. The core has an atomic $\mathrm{Ti} / \mathrm{Cl}$ ratio around 0.5 while the surface presents an excess of $\mathrm{Ti}$ atoms relative to $\mathrm{Cl}$.

\section{NanoSIMS analytical protocol.}

The Ti isotope composition of experimental samples was measured using NanoSIMS at The University of Manchester with a spatial resolution of $c a$. 150-200 $\mathrm{nm}$. In most cases, analyses were carried out randomly on the samples by rastering area of $20 \times 20 \mu \mathrm{m}$ in size. In selected area, some features of interest were then imaged over $3 \times 3 \mu \mathrm{m}$ to $8 \times 8 \mu \mathrm{m}$ area. The measured $\mathrm{Ti}$ isotope ratios $(m \mathrm{Ti} / 48 \mathrm{Ti})$ are expressed using the $\delta^{m} \mathrm{Ti}$ notation ( $m$ standing for the masses $46,47,49$ or 50$)$.

For NanoSIMS analysis experimental products were gold coated and mounted on 1 inch holders. Analyses were carried out using an O- primary beam current of 15 pA (D1-2, $300 \mu \mathrm{m}$ diameter aperture), with an accelerating voltage of $16 \mathrm{kV}$. Each analysis was preceded by 10 min presputtering using a $100 \mathrm{pA}$ primary beam (D1-1, $750 \mu \mathrm{m}$ diameter aperture) rastered on the sample over $30 \mu \mathrm{m} \times 30 \mu \mathrm{m}$ area to eliminate any surface contamination. Secondary ionic species of ${ }^{12} \mathrm{C}^{+},{ }^{35} \mathrm{Cl}^{+},{ }^{46} \mathrm{Ti}^{+},{ }^{47} \mathrm{Ti}^{+},{ }^{48} \mathrm{Ti}^{+},{ }^{49} \mathrm{Ti}^{+}$and ${ }^{50} \mathrm{Ti}^{+}$were then collected simultaneously on seven electron multipliers in imaging mode for 20 to 30 frames (approximately 8 to $13 \mathrm{~min}$ ) from $20 \mu \mathrm{m} \times 20 \mu \mathrm{m}$ area, divided in $256 \times 256$ pixels, with a dwell time of $400 \mu \mathrm{s} /$ pixel. Some features of interest located in $20 \times 20 \mu \mathrm{m}$ area were then imaged using smaller raster sizes of between $3 \times 3 \mu \mathrm{m}$ and $8 \times 8 \mu \mathrm{m}$ and the same analytical conditions (see Table S1). In order to adequately resolve isobaric interferences of $\mathrm{Ti}$ hydrides on $\mathrm{Ti}$ isotopes (e.g., ${ }^{m-1} \mathrm{TiH}$ on ${ }^{m} \mathrm{Ti}$ ), the mass resolving power was set to 8000 (CAMECA definition) using a 20- $\mu \mathrm{m}$-wide entrance slit (ES3) at the entrance of the mass analyzer and a $200-\mu \mathrm{m}$-wide aperture slit (AS2). The vacuum in the analysis chamber remained constant at around $2-4 \times 10^{-9}$ mbar throughout the week-long analytical session.

All the data were processed off-line using the l'Image software package (L. Nittler, Carnegie Institution of Washington, Washington, DC). A 44 ns dead time was applied to all electron multipliers. Measured Ti isotopes were corrected for instrumental mass fractionation (IMF) based on $\mathrm{Ti}$ isotope ratios measured on a Ti-bearing synthetic organic powder (cyclopentadienyl-titanium dichloride) standard just after and just before a block of unknown analyses, and assuming natural $\mathrm{Ti}$ isotope abundances in this standard (e.g., $\delta^{46,47,49,50} \mathrm{Ti}=$ $0 \%$ ). Uncertainties associated with Ti isotope ratios presented in Table S1 are given at the $2 \sigma$ level, and combine reproducibility on $\mathrm{Ti}$ isotope ratios obtained on the standard data used to correct the corresponding unknown analyzes for IMF, and the counting statistic uncertainties associated with each analysis. Over the week-long analytical session, the overall reproducibility obtained on the cyclopentadienyl-titanium dichloride standard was $\pm 5.5,4.8$, 
5.1 and $5.7 \%$ for $\delta^{46} \mathrm{Ti}, \delta^{47} \mathrm{Ti}, \delta^{49} \mathrm{Ti}$ and $\delta^{50} \mathrm{Ti}$, respectively $(2$ standard deviation, $\mathrm{n}=42$; see Supplementary Fig.3).

\section{Chemical and isotopic compositions in the grain reported in Fig. 2a}

\begin{tabular}{|c|c|c|c|c|c|c|c|c|c|c|c|c|}
\hline & $\begin{array}{l}\text { Threshold (cps } \\
\left.{ }_{48} \mathrm{Ti}^{+} \times 10^{3}\right)\end{array}$ & $\begin{array}{c}{ }^{12} \mathrm{C} \\
\text { (cps) }\end{array}$ & $\begin{array}{r}{ }^{35} \mathrm{Cl} \\
(\mathrm{cps})\end{array}$ & $\begin{array}{l}{ }^{48} \mathrm{Ti} \\
\text { (cps) }\end{array}$ & $\begin{array}{c}\delta^{46} \mathrm{Ti} \\
(\% \mathrm{o})\end{array}$ & $\begin{array}{c}2 \sigma \\
(\%)\end{array}$ & $\begin{array}{l}\delta^{47} \mathrm{Ti} \\
(\% \mathrm{o})\end{array}$ & $\begin{array}{l}2 \sigma \\
(\%)\end{array}$ & $\begin{array}{l}\delta^{49} \mathrm{Ti} \\
(\%)\end{array}$ & $\begin{array}{c}2 \sigma \\
(\%)\end{array}$ & $\begin{array}{l}\delta^{50} \mathrm{Ti} \\
(\% \mathrm{o})\end{array}$ & $\begin{array}{l}2 \sigma \\
(\%)\end{array}$ \\
\hline Bulk & & 3.3 & 0.9 & 5389.8 & 33 & 10 & 61 & 9 & 63 & 9 & 92 & 9 \\
\hline [1] & $>12$ & 8.2 & 5.5 & 12359.9 & -192 & 95 & -214 & 141 & -221 & 98 & -250 & 103 \\
\hline [2] & $9.2-12$ & 4.2 & 1.5 & 9620.8 & -144 & 28 & -157 & 50 & -156 & 33 & -147 & 40 \\
\hline [3] & $6.6-9.2$ & 4.2 & 0.8 & 7244.2 & -92 & 16 & -67 & 12 & -62 & 16 & -33 & 15 \\
\hline [4] & $3.9-6.6$ & 3.3 & 0.7 & 5065.4 & 111 & 17 & 133 & 12 & 136 & 14 & 168 & 15 \\
\hline [5] & $1.3-3.9$ & 1.9 & 0.9 & 2707.1 & 244 & 52 & 345 & 31 & 324 & 36 & 367 & 50 \\
\hline [6] & $<1.3$ & 0.6 & 2.6 & 831.6 & 1241 & 286 & 1284 & 309 & 1181 & 352 & 1204 & 360 \\
\hline
\end{tabular}

Table 1: Intensity of ${ }^{12} \mathrm{C},{ }^{35} \mathrm{Cl}$ and ${ }^{48} \mathrm{Ti}$ and $\mathrm{Ti}$ isotope ratios obtained on different regions of interest, labeled [1] to [6], of a $c a .2 \mu \mathrm{m}$ Ti-rich grain shown in Figure 2. The threshold indicates the concentration boundaries (expressed in ${ }^{48} \mathrm{Ti}^{+}$ion count per sec) of the domains where the isotopic compositions have been determined.

\section{MIF model.}

Two general mechanisms have been proposed to account for the MIF effects:

(i) After the formation of the metastable molecule, the redistribution of the energy among its vibrational-rotational modes proceeds at a finite rate. This rate may not allow a statistical redistribution of states during the short lifetime of the metastable molecule ${ }^{24}$. Consequently, the available states for its stabilization may not be equal for symmetrical and asymmetrical metastable molecules. For the same reasons of symmetry, it has also been proposed that the collisional energy transfer in the deactivation of the metastable molecule may not be the same for symmetrical and non-symmetrical molecules. Extensive numerical computation of these 
effects has been reported in the literature in light of the various isotopic fractionation behaviors observed for ozone and for sulfur isotopomers $25,28-30$.

(ii) The scattering cross sections describing the encounter between two indistinguishable isotopes (particles) have a higher degree of symmetry compared to those between distinguishable isotopes. The quantum-mechanical effect of this second interpretation (ii) was introduced in classical physics to fulfill the requirement of the exclusion principle, giving numerical results that reproduce most of the experimental data obtained for ozone ${ }^{6}$. The physical interpretation of (ii) is reported in Supplementary Information 5. As long as MIF patterns are concerned, both interpretations have similar numerical consequences.

Consider the isotopic exchange reaction rate between $j \mathrm{Ti}$ and $i \mathrm{TiM}$ :

$$
\mathrm{jTi}+\mathrm{iTiM} \rightarrow[\mathrm{jTi} \mathrm{iTiM}]^{*} \rightarrow \mathrm{iTi}+\mathrm{jTiM}
$$

$\mathrm{M}$ is $\mathrm{Cl}_{4}$ in the present case, $i$ and $j$ are the titanium isotope mass numbers and [iTiTiM]* the so-called "metastable molecule" or "activated complex". The reaction rate $r l$ for the formation of [ $\left[\mathrm{TiiTiM}^{*}\right.$ is written as:

$$
r l=[\mathrm{jTi}] \cdot\left[{ }^{\mathrm{T} T i M}\right] \cdot k_{f}^{i-j} / k_{D}
$$

with $k_{f}^{i-j}$ the forward reaction rate constant and $k_{D}$ the dissociation rate constant (subscript D for dissociation) of [jTiTiM]* and in brackets the densities of jTi or iTiM. The rate constant $k_{D}$ is interpreted as the average lifetime $\bar{\tau}\left(\bar{\tau}=1 / k_{D}\right)$ of $\left[\mathrm{jTi}{ }^{\mathrm{i} T i M}\right]^{*}$. After a duration $\bar{\tau}$, [jTi iTiM]* spontaneously dissociates.

Similarly, for $i=j=48$ we can write:

$$
r 2=\left[{ }^{48} \mathrm{Ti}\right] \cdot\left[{ }^{48} \mathrm{TiM}\right] \cdot k_{f}^{48-48} / k_{D I}
$$

with $k_{D I}$ the dissociation rate constant of [iTiTiM]* when isotopes are indistinguishable; i.e. ${ }^{48} \mathrm{Ti}$ and ${ }^{48} \mathrm{TiM}$ in reaction (3) (subscript I in $k_{D I}$ ). The reaction rate ratio $\mathrm{R}$ is:

$$
R=r 1 / r 2=\left\{x(i) \cdot x(j) \cdot \alpha_{k f} i-j \cdot \eta_{j}\right\} /\{x(48)\}^{2}
$$

where $\alpha_{k f}{ }^{i-j}$ stands for the $k_{f}^{i-j /} k_{f} 48-48$ ratio. In the interpretation (ii), $v_{j}$ stands for the $k_{D I} / k_{D}$ ratio, i.e. for the mass-independent isotopic fractionation factor $\bar{\tau} / \bar{\tau}_{\text {I }}$. The densities drop out in $\mathrm{R}$ and are replaced by the relative abundances $x(i), x(j)$, etc of the isotopes $i, j$, etc. $(\Sigma x=1)$. As shown by detailed calculations on metastable ozone $^{6}, w_{j}$ contains an additional massdependent term because the dissociation rates are also mass-dependent (the heaviest species 
dissociating the fastest ${ }^{29}$ ). A second mass-dependent term should thus be introduced in $\mathrm{R}$ as $\alpha_{\eta}{ }^{i-j}$, giving:

$$
R=r 1 / r 2=\left\{x(i) \cdot x(j) \cdot \alpha_{k f}{ }^{i-j} \cdot \alpha_{\eta}{ }^{i-j} \cdot \eta\right\} /\{x(48)\}^{2}
$$

with:

$$
\eta_{j}=\alpha_{\eta}^{i-j} \cdot \eta
$$

Under this formalism, $\eta$ is (almost) constant. When $i=j, \eta=1\left(\eta=\bar{\tau}_{\mathrm{I}} / \bar{\tau}_{\mathrm{I}}\right)$. The massdependent variations can be approximated by the ratio of the reduced masses of the reactants 22 :

$$
\alpha^{i-j}=\left[\mu_{i-j}\right]^{b} /\left[\mu_{48-48}\right]^{b}
$$

with $b$ corresponding to an arbitrary parameter that dictates the magnitude of the isotopic fractionation. In the present experiment, the term $\alpha_{k f} f^{i-j}$ stands for the condensation rates for which $\delta^{m-l} \mathrm{Ti}>\delta^{m} \mathrm{Ti}$ while for $\alpha_{\eta^{i-j}}, \delta^{m-l} \mathrm{Ti}<\delta^{m} \mathrm{Ti}$.

This formalism can be used to calculate the multi isotopic patterns for chemical elements. In the present experiment, neglecting the possible mass dependent relations (e.g., $b=0)$ the experimental pattern is reproduced for $\eta=4$.

\section{Figures}

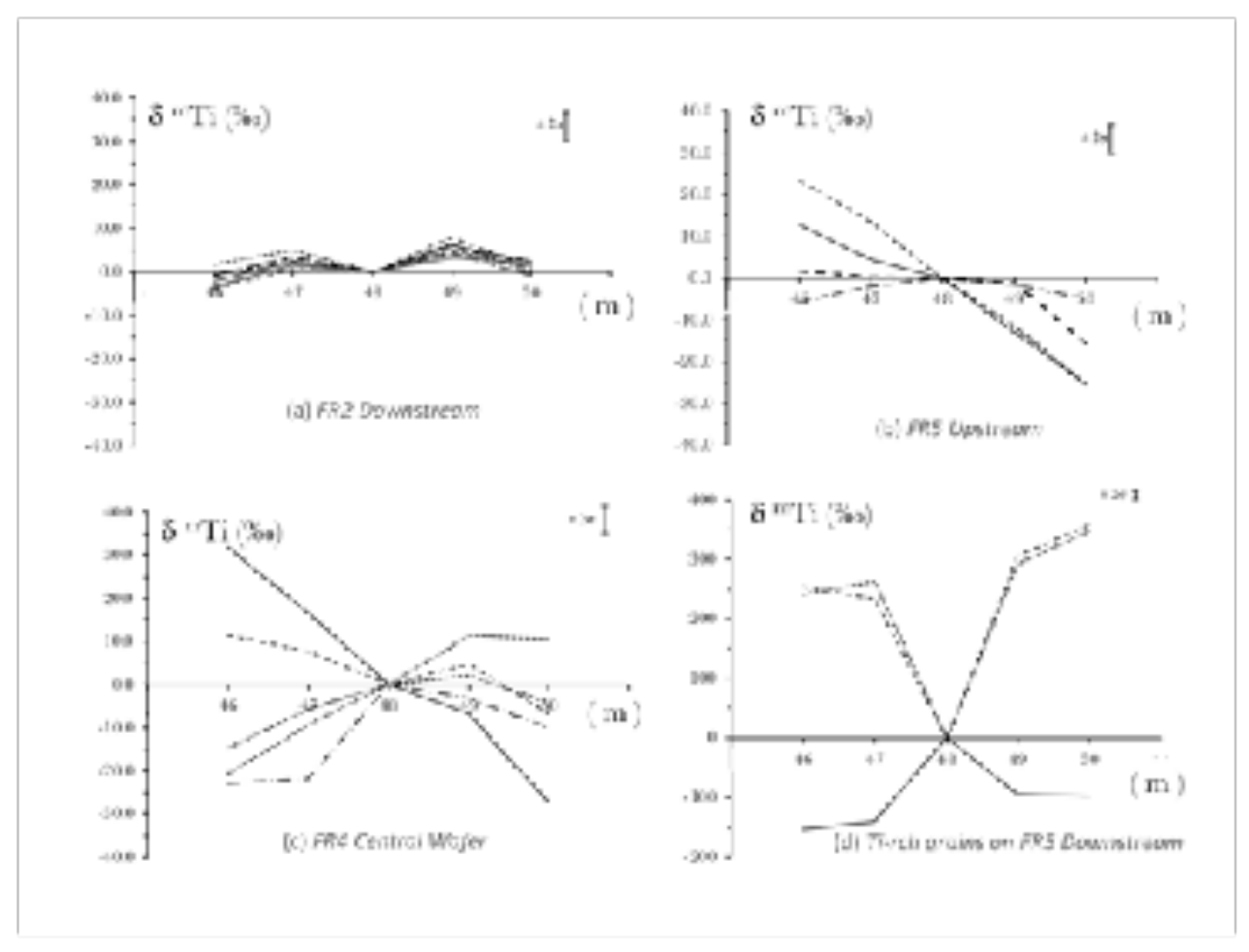


Figure 1
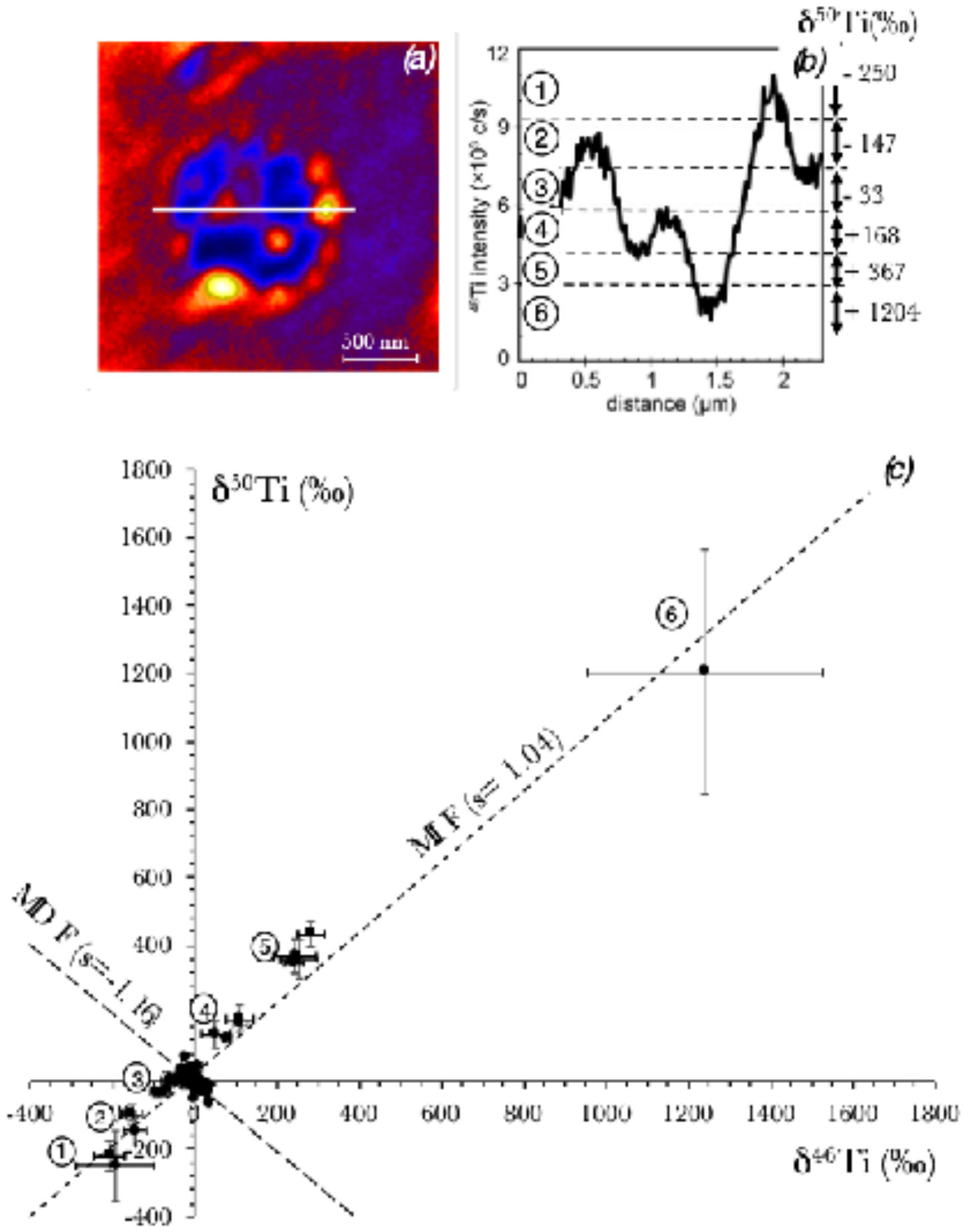

Figure 2 


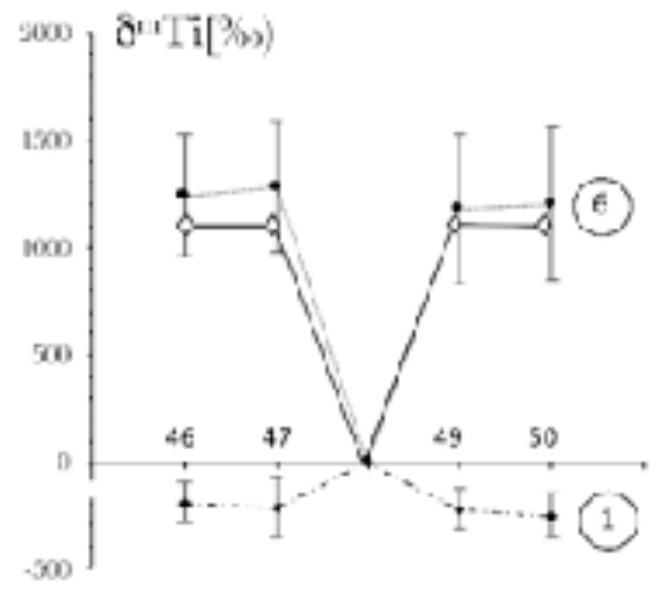

Figure 3 


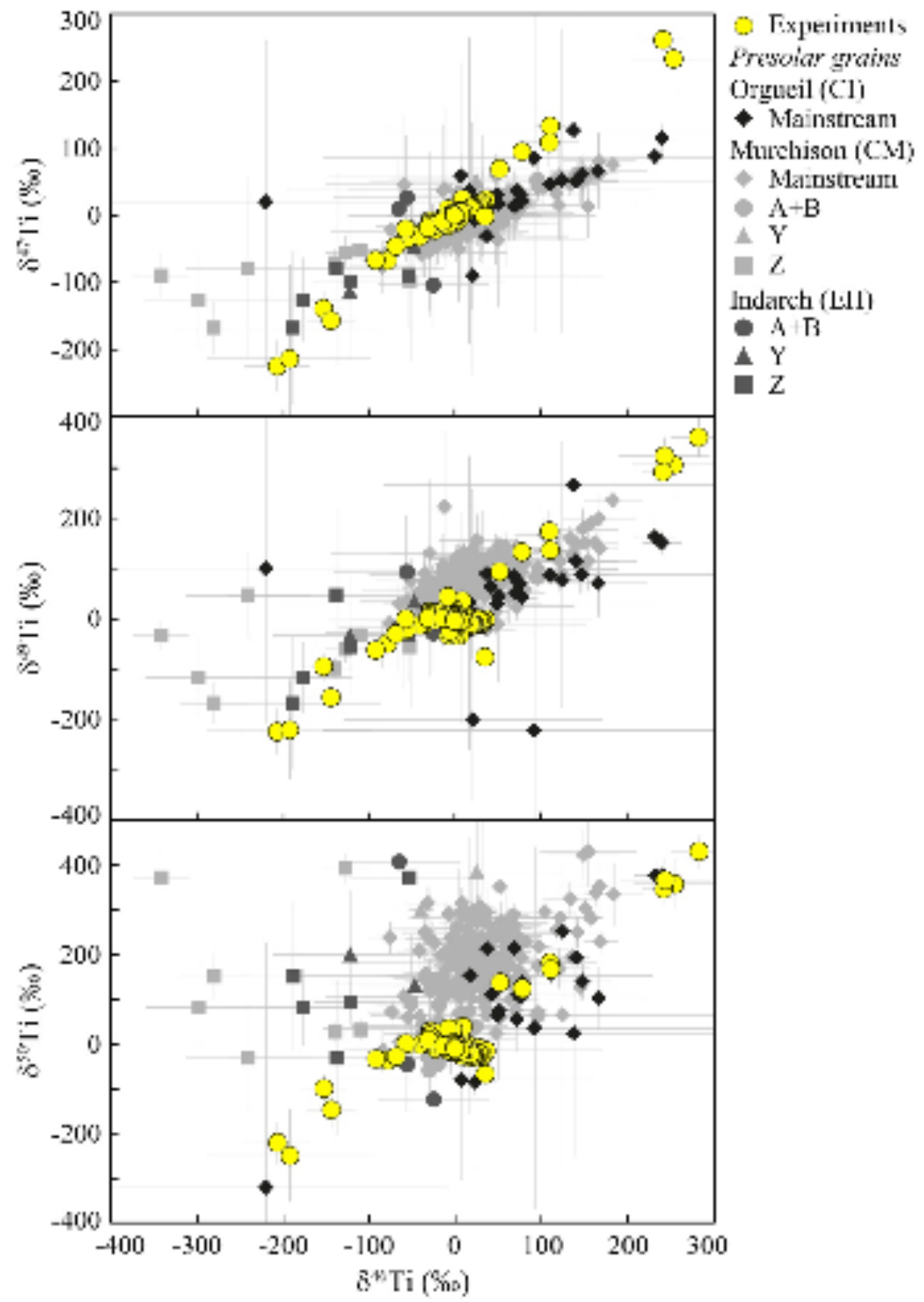

Figure 4 


\title{
Supplementary Informations
}

\section{Mass-Independent Fractionation of Titanium Isotopes and its Cosmochemical Implications}

\author{
François Robert ${ }^{*}$, Romain Tartèse ${ }^{2}$, Guillaume Lombardi ${ }^{3}$, Peter Reinhardt ${ }^{4}$, Mathieu \\ Roskosz ${ }^{1}$, Béatrice Doisneau ${ }^{1}$, Zhengbin Deng ${ }^{5}$, Marc Chaussidon ${ }^{5}$
}

\author{
Affiliations: \\ ${ }^{1}$ Muséum National d'Histoire Naturelle, Institut de Minéralogie, Physique des Matériaux \\ et Cosmochimie, CNRS UMR 7590, 61 rue Buffon, 75005 Paris, France. \\ 2Department of Earth and Environmental Sciences, The University of Manchester, \\ Oxford Road, Manchester M13 9PL, UK. \\ ${ }^{3}$ Laboratoire des Laboratoire des Sciences des Procédés et des Matériaux, CNRS, \\ Université Paris 13, Sorbonne Paris Cité, 93430 Villetaneuse, France \\ ${ }^{4}$ Laboratoire de Chimie Théorique, Sorbonne Université et CNRS UMR 7616, 4 place \\ Jussieu, 75252 Paris Cedex 05, France. \\ ${ }^{5}$ Université de Paris, Institut de Physique du Globe de Paris, CNRS, F-75005 Paris, \\ France.
}




\section{Plasma Experiments - Samples}

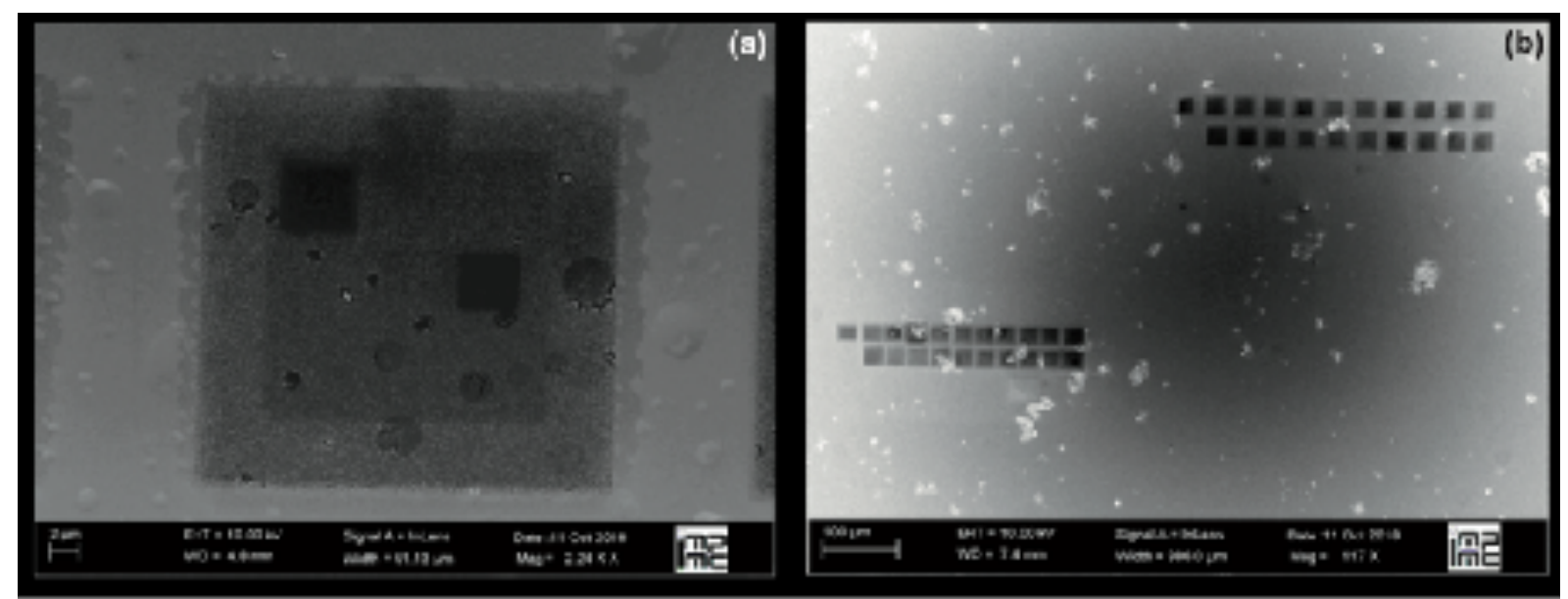

Supplementary Fig.1: SEM micrographs of area analyzed with the NanoSIMS of carbonaceous matter deposited on a silicon wafer (a) Sample FR5-Downstream. The largest square are presputtured area, smaller squares represent NanoSIMS analyses on individual grain. Circular structures (grains) are observed all over the sample. Isotopic analyses across an individual grain are reported in Figs. $2 \mathrm{~b}$ and $2 \mathrm{c}$ (cf. text). A cross section of these deposits is shown in Supplementary Fig.2. (b) Sample FR4-Central. No particular circular structure could be observed in this sample. NanoSims sputtered areas appear as black squares.

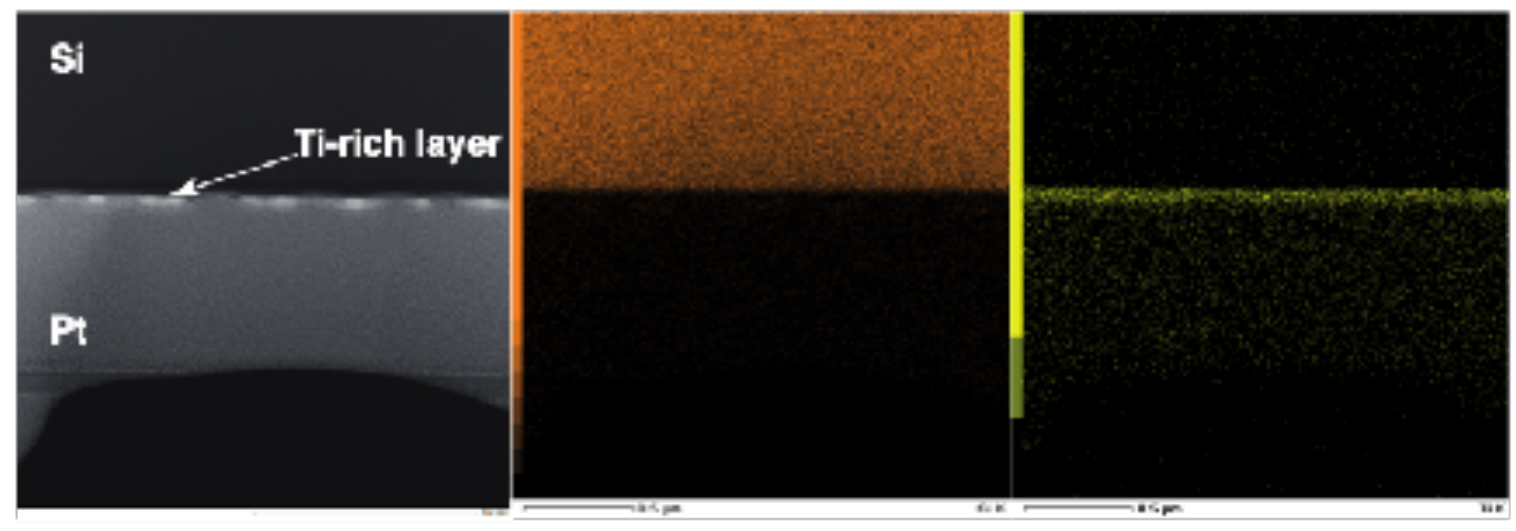

Supplementary Fig.2: Successively from left to right: (1) STEM image, (2) elemental Si (Wafer) and (3) elemental Ti compositional maps. Maps are only qualitative and no baseline corrections were made; hence the apparent presence of Ti traces in the Pt and Si layers. Point analysis however did not confirm the presence of $\mathrm{Ti}$ in these two layers. The thickness of the deposited Ti-rich layer is around $50 \mathrm{~nm}$. 


\section{NanoSIMS analytical protocol}

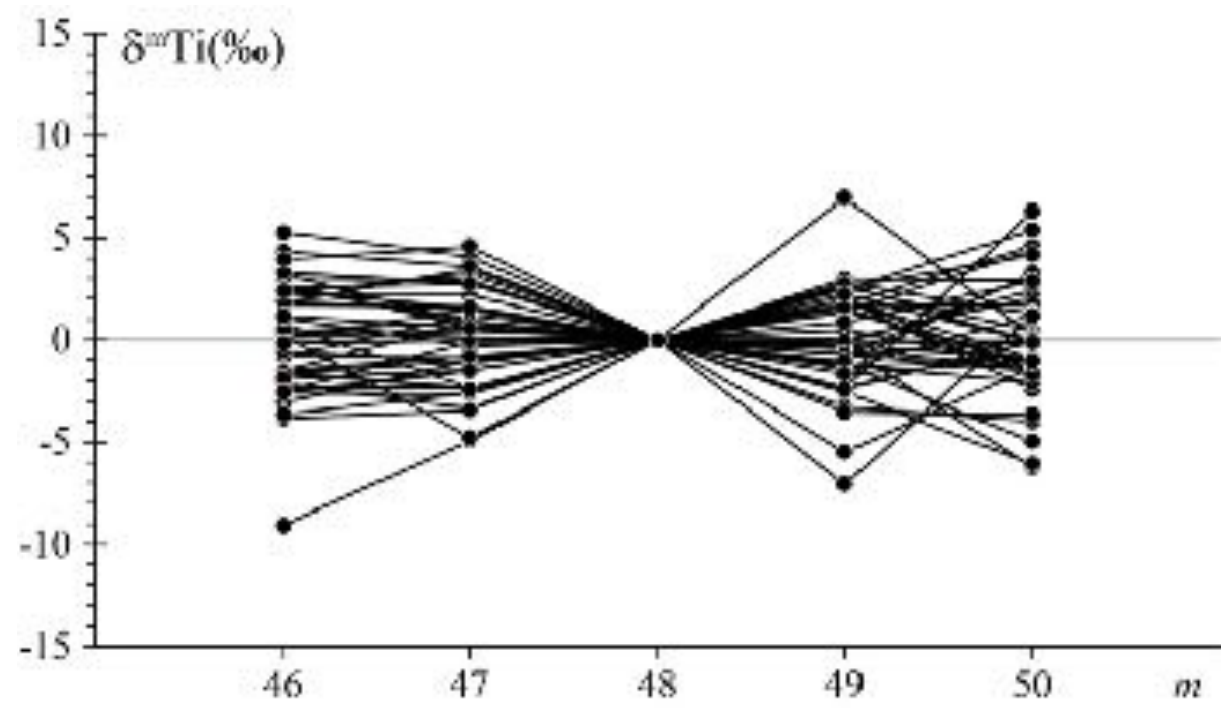

Supplementary Fig.3: $\delta^{46,47,49,50} \mathrm{Ti}$ values obtained on the cyclopentadienyl-titanium dichloride standard over the course of the week long analytical session $(n=42)$. The reproducibility is of the order of $\pm 6 \%$ o $(2 \sigma$; cf. text $)$.

3. Supplementary Table 1. NanoSIMS results for the three different experiments FR2, FR4 and FR5 (mixing $\mathrm{TiCl}_{4} /$ pentane ratio $=2: 1$ and $\mathrm{N}_{2}$ as the carrier gas). A dusty plasma (formation of grains) is observed in FR5 likely caused by the longer residence time $(1 / 5 \mathrm{~s})$ of the gas in the plasma than for FR2 and $F R 4$ experiments (1/10 s). For $F R 2$, no wafer was put in the center of the discharge and OM was collected from the glass walls. Error bars include statistical errors (ion counting statistic) and the reproducibility on the standard. These data can also be found as an Excel file (Supplementary Data 1).

\begin{tabular}{|c|c|c|c|c|c|c|c|c|c|c|c|c|}
\hline Sample and Analysis name & Notes & ${ }^{12} \mathrm{C}$ (cps) & ${ }^{35} \mathrm{Cl}$ (cps) & ${ }^{48} \mathrm{Ti}$ (cps) & $\begin{array}{l}\delta^{46} \mathrm{Ti} \\
(\%)\end{array}$ & $\begin{array}{c}2 \sigma \\
(\%)\end{array}$ & $\begin{array}{l}\delta^{47} \mathrm{Ti} \\
(\%)\end{array}$ & $\begin{array}{c}2 \sigma \\
(\%)\end{array}$ & $\begin{array}{l}\delta^{49} \mathrm{Ti} \\
(\%)\end{array}$ & $\begin{array}{c}2 \sigma \\
(\%)\end{array}$ & $\begin{array}{c}\delta^{50} \mathrm{Ti} \\
(\%)\end{array}$ & $\begin{array}{l}2 \sigma \\
(\%)\end{array}$ \\
\hline \multicolumn{13}{|l|}{ \#4 Upstream Wafer } \\
\hline FR4_Amont_1 & $20 \times 20 \mu \mathrm{m}$ & 4.44E-01 & $1.26 \mathrm{E}+00$ & $4.04 \mathrm{E}+04$ & -2.2 & 3.4 & -5.7 & 3.7 & -6.6 & 6.6 & -9.1 & 4.9 \\
\hline FR4_Amont_2 & $20 \times 20 \mu \mathrm{m}$ & $3.45 \mathrm{E}-01$ & $2.77 \mathrm{E}+00$ & $3.84 \mathrm{E}+04$ & -2.8 & 3.5 & -5.7 & 3.7 & -4.8 & 6.6 & -5.2 & 4.9 \\
\hline FR4_Amont_3 & $20 \times 20 \mu \mathrm{m}$ & $2.39 \mathrm{E}+00$ & $1.26 \mathrm{E}+00$ & $2.74 \mathrm{E}+04$ & -14.0 & 3.5 & -11.1 & 3.7 & 3.2 & 6.6 & 8.0 & 5.0 \\
\hline FR4_Amont_4 & $20 \times 20 \mu \mathrm{m}$ & $6.19 \mathrm{E}+00$ & $2.16 \mathrm{E}+00$ & $5.08 \mathrm{E}+04$ & -5.7 & 3.4 & -1.4 & 3.6 & 3.2 & 6.5 & 6.6 & 4.9 \\
\hline
\end{tabular}


\#4 Central Wafer

FR4 Centre 10Sep18-PM Chain 1 FR4_Centre_10Sep18-PM_Chain_2

FR4_Centre_10Sep18-

PM_Chain_v2_1

FR4_Centre_10Sep18-

PM_Chain_v2_2

FR4_Centre_10Sep18-

PM_Chain_v2_3

FR4_Centre_10Sep18-

PM_Chain_v2_4

FR4_Centre 10Sep18-

PM_Chain_v2_5

FR4_Centre_10Sep18-

PM_Chain_v2_6

FR4 Centre 10Sep18-

PM_Chain_v2_7

FR4_Centre_10Sep18-

PM Chain v2 8

FR4_Centre_10Sep18-

PM_Chain_v2_9

FR4_Centre_10Sep18-

PM_Chain_v2_10

FR4 Centre 10Sep18-

PM_Chain_v2_11

FR4_Centre_10Sep18-

PM_Chain_v2_12

FR4 Centre 10Sep18-

PM_Chain_v2_13

FR4_Centre_10Sep18-

PM_Chain_v2_14

FR4_Centre_10Sep18-

PM_Chain_v2_15

FR4_Centre_10Sep18-

PM_Chain_v2_16

FR4_Centre_10Sep18-

PM_Chain_v2_17

FR4 Centre 10Sep18-

PM_Chain_v2_18

\#4 Central Wafer

FR4_Centre_11Sep18-night_1

FR4_Centre_11Sep18-night_2

FR4_Centre_11Sep18-night_3

FR4_Centre_11Sep18-night 4

FR4_Centre_11Sep18-night_4

FR4_Centre_11Sep18-night_5

FR4_Centre_11Sep18-night_5

FR4_Centre_11Sep18-night_6

FR4_Centre_11Sep18-night_7

FR4_Centre_11Sep18-night_8

FR4_Centre_11Sep18-night_9

FR4_Centre_11Sep18-night_10

FR4_Centre_11Sep18-night_11

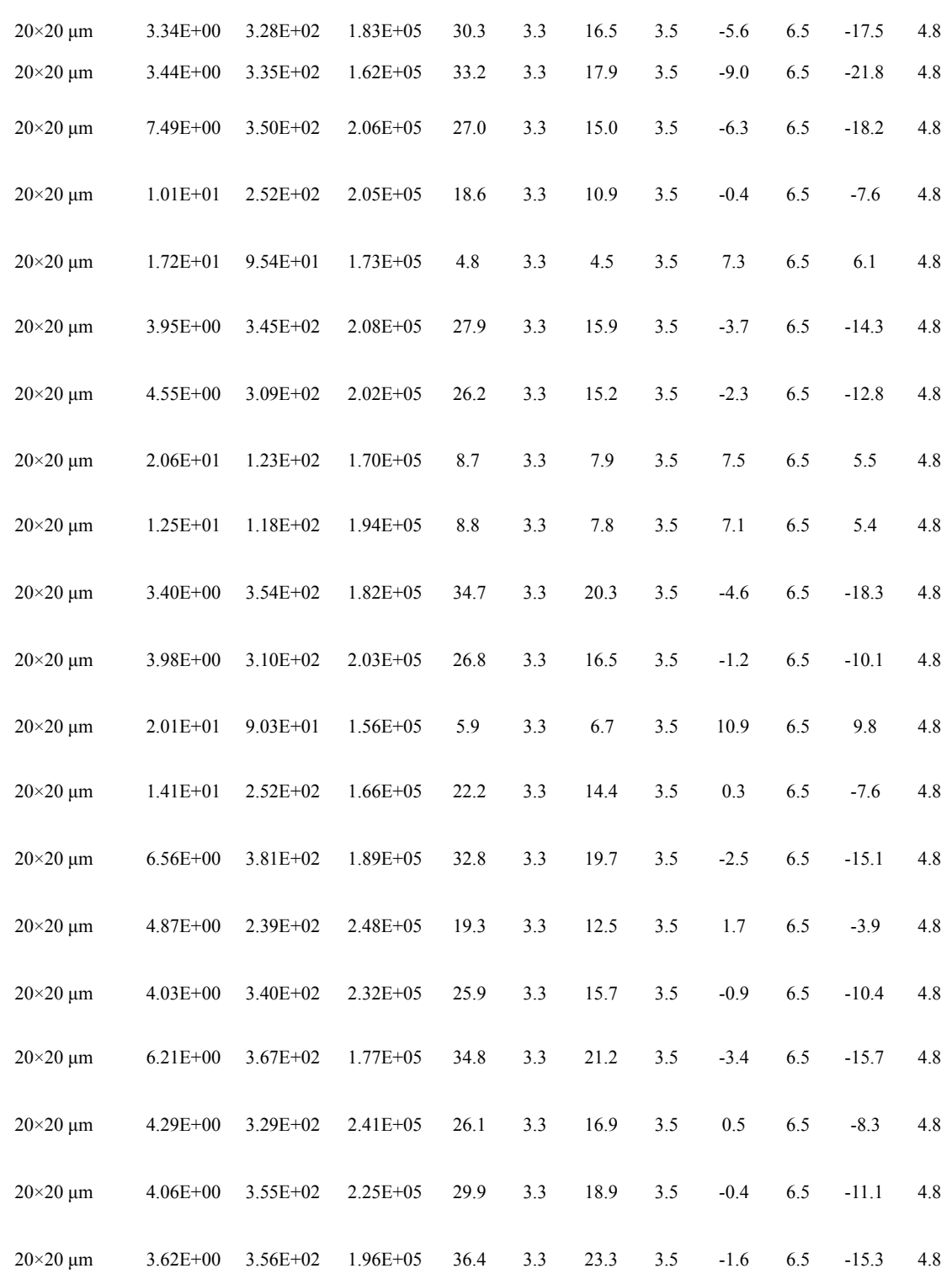

$\begin{array}{llllllllllll}20 \times 20 \mu \mathrm{m} & 3.33 \mathrm{E}+00 & 3.65 \mathrm{E}+02 & 1.98 \mathrm{E}+05 & 27.8 & 5.4 & 14.1 & 6.1 & -5.5 & 3.9 & -23.8 & 6.8 \\ 20 \times 20 \mu \mathrm{m} & 3.78 \mathrm{E}+00 & 3.63 \mathrm{E}+02 & 2.10 \mathrm{E}+05 & 24.6 & 5.4 & 14.0 & 6.1 & -4.6 & 3.9 & -21.6 & 6.8 \\ 20 \times 20 \mu \mathrm{m} & 1.99 \mathrm{E}+01 & 9.15 \mathrm{E}+01 & 1.49 \mathrm{E}+05 & 0.7 & 5.4 & 1.8 & 6.1 & 6.4 & 3.9 & -0.4 & 6.8 \\ 20 \times 20 \mu \mathrm{m} & 2.05 \mathrm{E}+01 & 1.41 \mathrm{E}+01 & 2.74 \mathrm{E}+04 & -20.3 & 5.6 & -13.4 & 6.3 & 7.3 & 4.3 & 9.2 & 7.1 \\ \text { Ti-rich ROI } & 1.49 \mathrm{E}+01 & 2.86 \mathrm{E}+01 & 5.91 \mathrm{E}+04 & -22.9 & 9.3 & -21.8 & 9.9 & -3.2 & 9.9 & -10.0 & 11.5 \\ 20 \times 20 \mu \mathrm{m} & 2.16 \mathrm{E}+01 & 1.17 \mathrm{E}+01 & 2.39 \mathrm{E}+04 & -22.1 & 5.6 & -10.1 & 6.3 & 6.9 & 4.4 & 8.0 & 7.1 \\ \text { Ti-rich ROI } & 2.15 \mathrm{E}+01 & 4.37 \mathrm{E}+01 & 9.02 \mathrm{E}+04 & -11.2 & 7.9 & -4.1 & 8.6 & 4.5 & 8.0 & 0.8 & 9.9 \\ 20 \times 20 \mu \mathrm{m} & 7.47 \mathrm{E}+00 & 2.33 \mathrm{E}+02 & 2.10 \mathrm{E}+05 & 15.1 & 5.4 & 9.2 & 6.1 & 1.0 & 3.9 & -11.7 & 6.8 \\ 20 \times 20 \mu \mathrm{m} & 2.87 \mathrm{E}+00 & 2.99 \mathrm{E}+02 & 1.70 \mathrm{E}+05 & 31.8 & 5.4 & 16.6 & 6.1 & -6.9 & 3.9 & -27.5 & 6.8 \\ 20 \times 20 \mu \mathrm{m} & 3.09 \mathrm{E}+00 & 3.28 \mathrm{E}+02 & 1.76 \mathrm{E}+05 & 30.9 & 5.4 & 16.9 & 6.1 & -5.6 & 3.9 & -26.2 & 6.8 \\ 20 \times 20 \mu \mathrm{m} & 2.98 \mathrm{E}+00 & 3.12 \mathrm{E}+02 & 1.71 \mathrm{E}+05 & 31.7 & 5.4 & 16.7 & 6.1 & -7.6 & 3.9 & -27.1 & 6.8 \\ 20 \times 20 \mu \mathrm{m} & 3.11 \mathrm{E}+00 & 3.29 \mathrm{E}+02 & 1.80 \mathrm{E}+05 & 30.4 & 5.4 & 17.5 & 6.1 & -5.1 & 3.9 & -25.2 & 6.8 \\ 20 \times 20 \mu \mathrm{m} & 3.07 \mathrm{E}+00 & 3.28 \mathrm{E}+02 & 1.77 \mathrm{E}+05 & 31.1 & 5.4 & 16.4 & 6.1 & -6.6 & 3.9 & -25.5 & 6.8\end{array}$


FR4_Centre_11Sep18-night_12

FR4_Centre_11Sep18-night_13

FR4_Centre_11Sep18-night_14

FR4_Centre_11Sep18-night_15

FR4_Centre_11Sep18-night_16

FR4_Centre_11Sep18-night_16

FR4_Centre_11Sep18-night_17

FR4_Centre 11Sep18-night 18

FR4_Centre_11Sep18-night_19

FR4_Centre_11Sep18-night_20

\#5 Downstream Wafer

FR5_Aval_12Sep18_1

FR5_Aval_12Sep18_1

FR5_Aval_12Sep18_2

FR5_Aval_12Sep18_2

FR5_Aval_12Sep18_3

FR5_Aval_12Sep18_3

FR5_Aval_12Sep18_3

\#5 Downstream Wafe

FR5_Aval_12Sep18_Anomaly_2

FR5_Aval_12Sep18_Anomaly_2

FR5_Aval_12Sep18_Anomaly_2

FR5_Aval_12Sep18_Anomaly_3

FR5_Aval_12Sep18_Anomaly_3

FR5_Aval_12Sep18 Anomaly_3

FR5_Aval_12Sep18_Anomaly_4

FR5_Aval_12Sep18_Anomaly_4

FR5_Aval_12Sep18_Anomaly_4

\#4 Central Wafer

FR4_Centre_12Sep18_Anomaly_1

FR4_Centre_12Sep18_Anomaly_1

FR4_Centre_12Sep18_Anomaly_1

FR4_Centre_12Sep18_Anomaly_1

FR4_Centre_12Sep18_Anomaly_2

FR4_Centre_12Sep18_Anomaly_2

\#5 Upstream Wafer

FR5_Amont_12Sep18_PM_1

FR5_Amont_12Sep18_PM_2

FR5_Amont_12Sep18_PM_3

FR5 Amont 12Sep18 PM b 1

FR5_Amont_12Sep18_PM_b_2

FR5_Amont_12Sep18_PM_b_3

$\begin{array}{llllllllllll}20 \times 20 \mu \mathrm{m} & 3.12 \mathrm{E}+00 & 4.51 \mathrm{E}+02 & 1.88 \mathrm{E}+05 & 28.3 & 5.4 & 15.4 & 6.1 & -4.5 & 3.9 & -23.2 & 6.8 \\ 20 \times 20 \mu \mathrm{m} & 3.13 \mathrm{E}+00 & 3.50 \mathrm{E}+02 & 1.81 \mathrm{E}+05 & 30.7 & 5.4 & 16.5 & 6.1 & -4.4 & 3.9 & -23.7 & 6.8 \\ 20 \times 20 \mu \mathrm{m} & 2.92 \mathrm{E}+00 & 3.04 \mathrm{E}+02 & 1.68 \mathrm{E}+05 & 32.3 & 5.4 & 17.8 & 6.1 & -6.3 & 3.9 & -26.9 & 6.8 \\ 20 \times 20 \mu \mathrm{m} & 1.09 \mathrm{E}+01 & 1.60 \mathrm{E}+02 & 1.65 \mathrm{E}+05 & 11.3 & 5.4 & 7.9 & 6.1 & 4.7 & 3.9 & -6.9 & 6.8 \\ 20 \times 20 \mu \mathrm{m} & 2.01 \mathrm{E}+01 & 1.37 \mathrm{E}+01 & 2.70 \mathrm{E}+04 & -21.4 & 5.6 & -11.1 & 6.3 & 11.1 & 4.3 & 9.2 & 7.1 \\ \text { Ti-rich ROI } & 2.45 \mathrm{E}+01 & 3.60 \mathrm{E}+01 & 6.10 \mathrm{E}+04 & -14.8 & 8.3 & -5.8 & 8.9 & 2.2 & 8.5 & -4.4 & 10.3 \\ 20 \times 20 \mu \mathrm{m} & 2.03 \mathrm{E}+01 & 1.11 \mathrm{E}+01 & 2.28 \mathrm{E}+04 & -20.7 & 5.6 & -9.3 & 6.3 & 11.3 & 4.4 & 10.3 & 7.1 \\ 20 \times 20 \mu \mathrm{m} & 2.00 \mathrm{E}+01 & 6.10 \mathrm{E}+01 & 9.55 \mathrm{E}+04 & -0.4 & 5.4 & 2.4 & 6.1 & 9.3 & 4.0 & 2.7 & 6.8 \\ 20 \times 20 \mu \mathrm{m} & 3.66 \mathrm{E}+00 & 3.67 \mathrm{E}+02 & 1.84 \mathrm{E}+05 & 31.3 & 5.4 & 18.2 & 6.1 & -4.0 & 3.9 & -23.9 & 6.8 \\ 20 \times 20 \mu \mathrm{m} & 3.49 \mathrm{E}+00 & 3.65 \mathrm{E}+02 & 1.96 \mathrm{E}+05 & 27.7 & 5.4 & 15.5 & 6.1 & -2.7 & 3.9 & -20.9 & 6.8\end{array}$

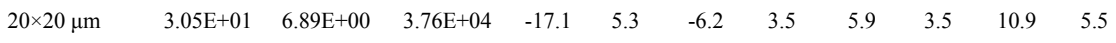

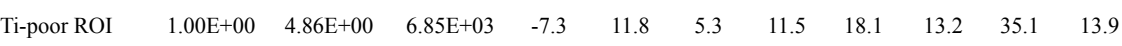

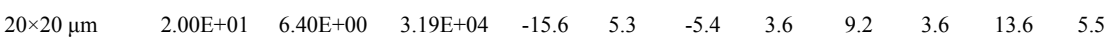

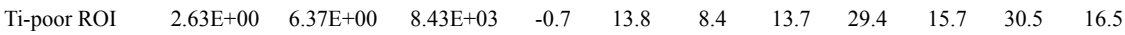

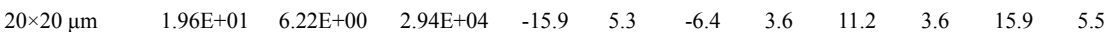

$\begin{array}{llllllllllll}\text { Ti-poor ROI } & 9.66 \mathrm{E}-01 & 2.12 \mathrm{E}+00 & 3.16 \mathrm{E}+03 & 8.8 & 12.9 & 24.0 & 12.7 & 35.8 & 14.6 & 39.3 & 15.3\end{array}$

$\begin{array}{llllllllllll}\text { Ti-rich ROI } & 1.91 \mathrm{E}+01 & 1.08 \mathrm{E}+01 & 4.75 \mathrm{E}+04 & -23.6 & 7.8 & -12.2 & 6.9 & 5.9 & 7.7 & 2.2 & 8.9\end{array}$

\begin{tabular}{|c|c|c|c|c|c|c|c|c|c|c|c|}
\hline $3 \times 3 \mu \mathrm{m}$ & $3.26 \mathrm{E}+00$ & $8.80 \mathrm{E}-01$ & $5.36 \mathrm{E}+03$ & -27.1 & 7.8 & -8.2 & 5.8 & 10.0 & 7.0 & 26.8 & 7.0 \\
\hline Ti-rich ROI & $7.80 \mathrm{E}+00$ & $1.67 \mathrm{E}+00$ & $1.08 \mathrm{E}+04$ & $\begin{array}{c}-206 . \\
7\end{array}$ & 36.8 & $\begin{array}{c}-225 . \\
0\end{array}$ & 38.4 & $\begin{array}{c}-224 \\
1\end{array}$ & 45.0 & $\begin{array}{c}-220 . \\
8\end{array}$ & 45.6 \\
\hline Ti-poor ROI & $9.21 \mathrm{E}-01$ & $1.33 \mathrm{E}+00$ & $1.66 \mathrm{E}+03$ & 283.5 & 32.5 & 393.4 & 32.3 & 360.5 & 38.0 & 431.5 & 37.6 \\
\hline $3 \times 3 \mu \mathrm{m}$ & $3.63 \mathrm{E}+00$ & 7.93E-01 & $5.75 \mathrm{E}+03$ & -29.4 & 7.6 & -9.3 & 5.6 & 14.5 & 6.8 & 28.7 & 6.8 \\
\hline Ti-rich ROI & $4.06 \mathrm{E}+00$ & $2.03 \mathrm{E}+00$ & $1.21 \mathrm{E}+04$ & $\begin{array}{c}-152 . \\
7\end{array}$ & 24.8 & $\begin{array}{c}-139 \\
6\end{array}$ & 25.2 & -94.7 & 28.8 & -98.9 & 29.3 \\
\hline Ti-poor ROI & 9.45E-01 & 8.40E-01 & $9.37 \mathrm{E}+02$ & 254.5 & 47.3 & 233.1 & 49.5 & 306.2 & 56.1 & 358.0 & 55.9 \\
\hline $4 \times 4 \mu \mathrm{m}$ & $4.70 \mathrm{E}+00$ & 7.39E-01 & $8.61 \mathrm{E}+03$ & -28.6 & 7.1 & -17.9 & 4.7 & 12.6 & 5.8 & 28.2 & 5.8 \\
\hline Ti-rich ROI & $1.03 \mathrm{E}+01$ & $4.59 \mathrm{E}+00$ & $2.88 \mathrm{E}+04$ & -36.2 & 11.6 & -24.8 & 10.7 & -10.8 & 12.6 & 4.9 & 12.6 \\
\hline -poor ROI & $1.88 \mathrm{E}+00$ & $2.82 \mathrm{E}-01$ & $3.41 \mathrm{E}+03$ & 242.0 & 24.5 & 261.6 & 24.7 & 291.9 & 28.5 & 347.2 & 28.4 \\
\hline
\end{tabular}

$\begin{array}{cccccccccccc}6 \times 6 \mu \mathrm{m} & 3.71 \mathrm{E}+01 & 2.82 \mathrm{E}-01 & 8.04 \mathrm{E}+03 & -14.9 & 6.0 & -10.6 & 2.7 & 14.2 & 3.8 & 24.6 & 3.8 \\ \text { Ti-rich ROI } & 4.52 \mathrm{E}+01 & 2.82 \mathrm{E}-01 & 4.17 \mathrm{E}+04 & -2.5 & 6.9 & -1.5 & 4.4 & 18.5 & 5.5 & 20.5 & 5.5 \\ \text { Ti-rich Hotspot 1 } & 4.52 \mathrm{E}+01 & 2.82 \mathrm{E}-01 & 5.69 \mathrm{E}+04 & -2.1 & 8.2 & 1.1 & 6.4 & 21.6 & 7.7 & 18.6 & 7.8 \\ \text { Ti-rich Hotspot 2 } & 5.18 \mathrm{E}+01 & 2.82 \mathrm{E}-01 & 4.25 \mathrm{E}+04 & -2.1 & 9.7 & -5.1 & 8.5 & 14.2 & 10.0 & 33.9 & 10.0 \\ 4 \times 4 \mu \mathrm{m} & 2.45 \mathrm{E}+01 & 3.69 \mathrm{E}-01 & 9.68 \mathrm{E}+03 & -18.2 & 6.5 & -11.6 & 3.8 & 9.4 & 4.9 & 24.8 & 4.9 \\ \text { Ti-rich ROI } & 2.28 \mathrm{E}+01 & 6.42 \mathrm{E}-01 & 1.83 \mathrm{E}+04 & -41.1 & 9.3 & -31.6 & 7.9 & -11.7 & 9.3 & -0.4 & 9.4\end{array}$

$\begin{array}{llllllllllll}20 \times 20 \mu \mathrm{m} & 1.60 \mathrm{E}+01 & 6.66 \mathrm{E}+02 & 2.13 \mathrm{E}+05 & 13.0 & 6.1 & 4.5 & 5.1 & -12.8 & 4.2 & -25.5 & 6.0 \\ 20 \times 20 \mu \mathrm{m} & 1.32 \mathrm{E}+01 & 4.43 \mathrm{E}+02 & 1.39 \mathrm{E}+05 & 15.5 & 6.1 & 6.2 & 5.1 & -11.6 & 4.3 & -24.3 & 6.0 \\ 20 \times 20 \mu \mathrm{m} & 9.38 \mathrm{E}+00 & 3.10 \mathrm{E}+02 & 9.64 \mathrm{E}+04 & 19.1 & 6.1 & 9.5 & 5.1 & -13.9 & 4.3 & -27.0 & 6.0 \\ 20 \times 20 \mu \mathrm{m} & 1.25 \mathrm{E}+01 & 9.58 \mathrm{E}+02 & 2.45 \mathrm{E}+05 & 17.1 & 6.1 & 7.8 & 5.1 & -13.3 & 4.2 & -28.2 & 6.0 \\ 20 \times 20 \mu \mathrm{m} & 1.59 \mathrm{E}+01 & 9.10 \mathrm{E}+02 & 2.42 \mathrm{E}+05 & 18.4 & 6.1 & 8.1 & 5.1 & -14.9 & 4.2 & -29.8 & 6.0 \\ 20 \times 20 \mu \mathrm{m} & 1.80 \mathrm{E}+01 & 9.02 \mathrm{E}+02 & 2.49 \mathrm{E}+05 & 16.2 & 6.1 & 6.8 & 5.1 & -14.5 & 4.2 & -29.4 & 6.0\end{array}$


FR5_Amont_12Sep18_PM_b_4

FR5_Amont_12Sep18_PM_b_5

FR5_Amont_12Sep18_PM_b_6

FR5_Amont_12Sep18_PM_b_7

FR5_Amont_12Sep18_PM_b_8

FR5_Amont_12Sep18_PM_b_9

FR5_Amont_12Sep18_PM_b_9

FR5_Amont_12Sep18_PM_b_10

FR5_Amont_12Sep18_PM_b_11

FR5_Amont_12Sep18_PM_b_11

FR5_Amont_12Sep18_PM_b_12

FR5_Amont_12Sep18_PM_b_13

FR5_Amont_12Sep18_PM_b_14

FR5_Amont_12Sep18_PM_b_15

FR5_Amont_12Sep18_PM_b_15

FR5 Amont 12Sep18 PM b 16

FR5_Amont_12Sep18_PM_b_16

FR5_Amont_12Sep18_PM_b_17

FR5_Amont_12Sep18_PM_b_17

\#2 OM Central Powder

Ti-FR2_powder_13Sep18_Chain_1

Ti-FR2_powder_13Sep18_Chain_2

Ti-FR2_powder_13Sep18_Chain_3

Ti-FR2_powder_13Sep18_Chain_3

Ti-FR2_powder_13Sep18_Chain_4

Ti-FR2_powder_13Sep18_Chain_5

Ti-FR2_powder_13Sep18_Chain_6

\#5 Downstream Wafe

FR5_Aval_Im\#1_Anomaly1

FR5_Aval_Im\#1_Anomaly1

FR5_Aval_Im\#1_Anomaly1

FR5_Aval_Im\#1_Anomaly2

FR5_Aval_Im\#1_Anomaly2

FR5_Aval_Im\#1_Anomaly2

FR5_Aval_Im\#2_Anomaly1

FR5_Aval_Im\#2_Anomaly1

FR5_Aval_Im\#2_Anomaly1

FR5_Aval_Im\#2_Anomaly2

FR5_Aval_Im\#2_Anomaly2

FR5_Aval_Im\#2_Anomaly2

\#2 Downstream Wafer

FR2_Aval Chain 1

FR2_Aval_Chain_2

FR2_Aval_Chain_3

\begin{tabular}{cccccccccccc}
$20 \times 20 \mu \mathrm{m}$ & $2.81 \mathrm{E}+01$ & $5.90 \mathrm{E}+02$ & $2.49 \mathrm{E}+05$ & 11.0 & 6.1 & 6.0 & 5.1 & -11.2 & 4.2 & -22.5 & 6.0 \\
$20 \times 20 \mu \mathrm{m}$ & $9.80 \mathrm{E}+00$ & $1.53 \mathrm{E}+02$ & $5.77 \mathrm{E}+04$ & 8.3 & 6.2 & 4.6 & 5.2 & -10.1 & 4.4 & -18.5 & 6.1 \\
$20 \times 20 \mu \mathrm{m}$ & $1.19 \mathrm{E}+01$ & $1.50 \mathrm{E}+02$ & $6.58 \mathrm{E}+04$ & 12.8 & 6.1 & 6.8 & 5.1 & -8.3 & 4.4 & -19.7 & 6.1 \\
$20 \times 20 \mu \mathrm{m}$ & $2.29 \mathrm{E}+01$ & $2.78 \mathrm{E}+02$ & $1.69 \mathrm{E}+05$ & 9.1 & 6.1 & 3.5 & 5.1 & -9.1 & 4.2 & -18.0 & 6.0 \\
$20 \times 20 \mu \mathrm{m}$ & $1.87 \mathrm{E}+01$ & $7.34 \mathrm{E}+02$ & $2.25 \mathrm{E}+05$ & 15.7 & 6.1 & 8.5 & 5.1 & -11.2 & 4.2 & -24.0 & 6.0 \\
$20 \times 20 \mu \mathrm{m}$ & $6.84 \mathrm{E}+00$ & $2.91 \mathrm{E}+02$ & $9.87 \mathrm{E}+04$ & 16.9 & 6.1 & 7.8 & 5.1 & -13.2 & 4.3 & -26.1 & 6.0 \\
Ti-rich ROI & $4.78 \mathrm{E}+01$ & $5.95 \mathrm{E}+02$ & $3.49 \mathrm{E}+05$ & 1.8 & 7.7 & 0.4 & 7.0 & -1.2 & 7.1 & -15.5 & 8.3 \\
$20 \times 20 \mu \mathrm{m}$ & $1.31 \mathrm{E}+01$ & $4.23 \mathrm{E}+02$ & $1.81 \mathrm{E}+05$ & 15.3 & 6.1 & 7.4 & 5.1 & -12.6 & 4.2 & -25.7 & 6.0 \\
$20 \times 20 \mu \mathrm{m}$ & $5.25 \mathrm{E}+00$ & $2.43 \mathrm{E}+01$ & $1.18 \mathrm{E}+04$ & -5.8 & 6.5 & -1.8 & 5.7 & -1.4 & 5.1 & -4.9 & 6.7 \\
Ti-rich ROI & $8.74 \mathrm{E}+01$ & $6.71 \mathrm{E}+02$ & $3.73 \mathrm{E}+05$ & 4.9 & 8.0 & 5.4 & 7.5 & -8.5 & 7.7 & -20.9 & 8.8 \\
$20 \times 20 \mu \mathrm{m}$ & $7.23 \mathrm{E}+00$ & $5.55 \mathrm{E}+01$ & $2.26 \mathrm{E}+04$ & 9.1 & 6.3 & 5.8 & 5.4 & -10.1 & 4.7 & -15.9 & 6.3 \\
$20 \times 20 \mu \mathrm{m}$ & $9.07 \mathrm{E}+00$ & $3.81 \mathrm{E}+02$ & $1.15 \mathrm{E}+05$ & 23.5 & 6.1 & 12.1 & 5.1 & -13.7 & 4.3 & -29.4 & 6.0 \\
$20 \times 20 \mu \mathrm{m}$ & $8.86 \mathrm{E}+00$ & $2.88 \mathrm{E}+02$ & $8.11 \mathrm{E}+04$ & 23.4 & 6.1 & 13.5 & 5.1 & -11.3 & 4.3 & -25.5 & 6.0 \\
$20 \times 20 \mu \mathrm{m}$ & $8.38 \mathrm{E}+00$ & $4.08 \mathrm{E}+02$ & $1.30 \mathrm{E}+05$ & 21.1 & 6.1 & 11.8 & 5.1 & -10.5 & 4.3 & -26.8 & 6.0 \\
\hline Ti-rich ROI & $3.30 \mathrm{E}+01$ & $7.11 \mathrm{E}+02$ & $3.68 \mathrm{E}+05$ & 8.9 & 7.7 & 6.8 & 7.1 & -3.8 & 7.2 & -15.9 & 8.4 \\
$20 \times 20 \mu \mathrm{m}$ & $1.22 \mathrm{E}+01$ & $3.33 \mathrm{E}+02$ & $1.23 \mathrm{E}+05$ & 20.3 & 6.1 & 12.5 & 5.1 & -11.8 & 4.3 & -26.5 & 6.0 \\
Ti-rich ROI & $4.18 \mathrm{E}+01$ & $6.58 \mathrm{E}+02$ & $3.49 \mathrm{E}+05$ & 6.7 & 7.2 & 5.3 & 6.5 & -10.8 & 6.4 & -25.5 & 7.7 \\
$20 \times 20 \mu \mathrm{m}$ & $9.82 \mathrm{E}+00$ & $2.36 \mathrm{E}+02$ & $8.05 \mathrm{E}+04$ & 18.5 & 6.1 & 11.3 & 5.1 & -9.6 & 4.3 & -21.8 & 6.0 \\
Ti-rich ROI & $4.44 \mathrm{E}+01$ & $6.69 \mathrm{E}+02$ & $3.67 \mathrm{E}+05$ & 10.8 & 8.5 & 5.4 & 8.0 & -4.0 & 8.4 & -15.5 & 9.5
\end{tabular}

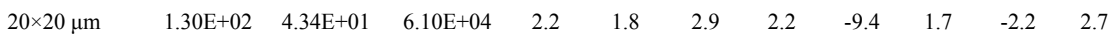

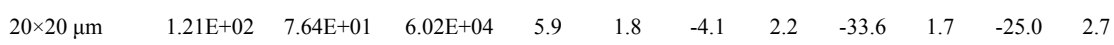

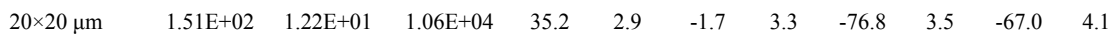

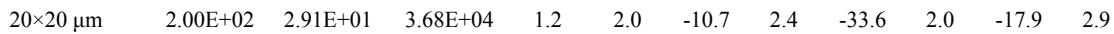

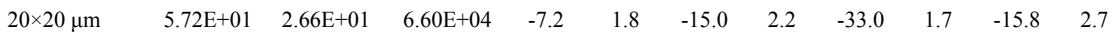

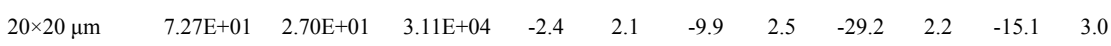

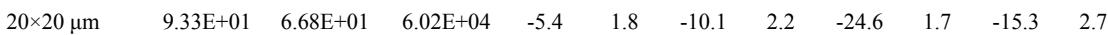

$\begin{array}{cccccccccccc}6 \times 6 \mu \mathrm{m} & 5.22 \mathrm{E}+00 & 1.65 \mathrm{E}+00 & 9.77 \mathrm{E}+03 & -30.3 & 2.7 & -15.5 & 3.0 & 3.2 & 2.9 & 12.6 & 3.6 \\ \text { Ti-rich ROI } & 8.64 \mathrm{E}+00 & 5.13 \mathrm{E}+00 & 2.12 \mathrm{E}+04 & -56.1 & 11.4 & -35.3 & 11.8 & -20.7 & 13.6 & -1.7 & 13.8 \\ \text { Ti-poor ROI } & 2.38 \mathrm{E}-01 & 2.54 \mathrm{E}-01 & 1.10 \mathrm{E}+03 & -8.0 & 14.3 & 9.6 & 14.9 & 43.9 & 17.0 & 34.3 & 17.4 \\ 8 \times 8 \mu \mathrm{m} & 1.56 \mathrm{E}+01 & 1.47 \mathrm{E}+00 & 1.70 \mathrm{E}+04 & -30.3 & 2.5 & -13.9 & 2.9 & 4.4 & 2.7 & 12.6 & 3.4 \\ \text { Ti-rich ROI } & 2.71 \mathrm{E}+01 & 1.28 \mathrm{E}+00 & 2.08 \mathrm{E}+04 & -78.2 & 9.3 & -67.4 & 9.8 & -49.3 & 11.1 & -35.6 & 11.4 \\ \text { Ti-poor ROI } & 2.74 \mathrm{E}+00 & 3.63 \mathrm{E}-01 & 3.94 \mathrm{E}+03 & 78.0 & 9.8 & 94.9 & 10.3 & 133.2 & 11.6 & 124.7 & 12.0 \\ 4 \times 4 \mu \mathrm{m} & 4.43 \mathrm{E}+00 & 1.03 \mathrm{E}+00 & 6.13 \mathrm{E}+03 & -30.4 & 3.8 & -14.2 & 4.1 & 6.5 & 4.3 & 19.5 & 4.8 \\ \text { Ti-rich ROI } & 2.67 \mathrm{E}+00 & 9.25 \mathrm{E}+00 & 1.45 \mathrm{E}+04 & -57.3 & 16.2 & -20.2 & 16.7 & -0.6 & 19.2 & 2.1 & 19.6 \\ \text { Ti-poor ROI } & 6.96 \mathrm{E}-02 & 2.78 \mathrm{E}-02 & 2.19 \mathrm{E}+02 & 52.1 & 35.0 & 68.9 & 36.4 & 94.1 & 41.9 & 137.5 & 41.8 \\ 5 \times 5 \mu \mathrm{m} & 8.43 \mathrm{E}+00 & 1.70 \mathrm{E}+00 & 1.10 \mathrm{E}+04 & -30.1 & 3.0 & -13.8 & 3.3 & 6.6 & 3.3 & 18.3 & 3.9 \\ \text { Ti-rich ROI } & 8.98 \mathrm{E}+00 & 6.01 \mathrm{E}+00 & 2.05 \mathrm{E}+04 & -68.5 & 9.3 & -45.9 & 9.7 & -30.0 & 11.0 & -27.0 & 11.3 \\ \text { Ti-poor ROI } & 1.07 \mathrm{E}-01 & 1.50 \mathrm{E}-01 & 4.09 \mathrm{E}+02 & 109.9 & 33.7 & 108.5 & 35.4 & 174.0 & 40.0 & 182.2 & 40.5\end{array}$

$\begin{array}{llllllllllll}20 \times 20 \mu \mathrm{m} & 1.42 \mathrm{E}+02 & 7.35 \mathrm{E}+01 & 5.08 \mathrm{E}+04 & -4.0 & 5.7 & 0.6 & 5.6 & 4.9 & 7.0 & 2.5 & 3.5\end{array}$

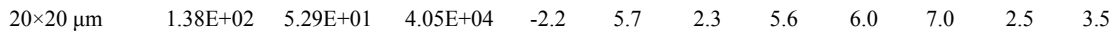

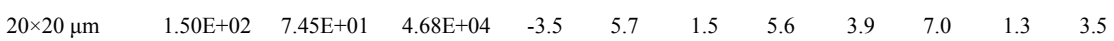




\begin{tabular}{|c|c|c|c|c|c|c|c|c|c|c|c|c|}
\hline FR2_Aval_Chain_4 & $20 \times 20 \mu \mathrm{m}$ & $1.99 \mathrm{E}+02$ & $1.41 \mathrm{E}+02$ & $5.38 \mathrm{E}+04$ & -0.8 & 5.7 & 2.5 & 5.6 & 7.9 & 7.0 & 1.1 & 3.5 \\
\hline FR2_Aval_Chain_5 & $20 \times 20 \mu \mathrm{m}$ & $1.99 \mathrm{E}+02$ & $1.41 \mathrm{E}+02$ & $5.28 \mathrm{E}+04$ & 1.7 & 5.7 & 5.1 & 5.6 & 6.6 & 7.0 & -0.1 & 3.5 \\
\hline FR2_Aval_Chain_6 & $20 \times 20 \mu \mathrm{m}$ & $1.88 \mathrm{E}+02$ & $1.15 \mathrm{E}+02$ & $4.31 \mathrm{E}+04$ & -0.9 & 5.7 & 3.3 & 5.6 & 4.3 & 7.0 & -0.9 & 3.5 \\
\hline FR2_Aval_Chain_7 & $20 \times 20 \mu \mathrm{m}$ & $1.96 \mathrm{E}+02$ & $1.32 \mathrm{E}+02$ & $5.02 \mathrm{E}+04$ & -3.7 & 5.7 & 1.5 & 5.6 & 3.2 & 7.0 & 2.1 & 3.5 \\
\hline FR2_Aval_Chain_8 & $20 \times 20 \mu \mathrm{m}$ & $1.56 \mathrm{E}+02$ & $7.16 \mathrm{E}+01$ & $3.72 \mathrm{E}+04$ & -1.0 & 5.7 & 3.0 & 5.7 & 4.9 & 7.1 & 0.4 & 3.6 \\
\hline \multicolumn{13}{|l|}{ \#2 Upstream Wafer } \\
\hline FR2_Amont_Chain_1 & $20 \times 20 \mu \mathrm{m}$ & $1.13 \mathrm{E}+02$ & $2.63 \mathrm{E}+02$ & $8.63 \mathrm{E}+04$ & -1.2 & 5.6 & -0.1 & 5.5 & -3.3 & 6.9 & -10.4 & 3.3 \\
\hline FR2_Amont_Chain_2 & $20 \times 20 \mu \mathrm{m}$ & $8.31 \mathrm{E}+01$ & $2.40 \mathrm{E}+02$ & $1.02 \mathrm{E}+05$ & -0.4 & 5.6 & 0.0 & 5.5 & -5.5 & 6.9 & -12.9 & 3.3 \\
\hline FR2_Amont_Chain_5 & $20 \times 20 \mu \mathrm{m}$ & $1.10 \mathrm{E}+02$ & $3.01 \mathrm{E}+02$ & $1.06 \mathrm{E}+05$ & 5.5 & 5.6 & 2.9 & 5.5 & -5.3 & 6.9 & -15.2 & 3.3 \\
\hline FR2_Amont_Chain_5 & Ti-rich ROI & $9.69 \mathrm{E}+01$ & $7.69 \mathrm{E}+02$ & $4.78 \mathrm{E}+05$ & -8.0 & 6.0 & -3.3 & 5.9 & 3.2 & 7.4 & 0.6 & 4.2 \\
\hline FR2_Amont_Chain_6 & $20 \times 20 \mu \mathrm{m}$ & $2.58 \mathrm{E}+01$ & $3.34 \mathrm{E}+01$ & $2.12 \mathrm{E}+04$ & -11.3 & 5.7 & -3.7 & 5.7 & -0.6 & 7.1 & -2.0 & 3.6 \\
\hline FR2_Amont_Chain_6 & Ti-rich ROI & $1.36 \mathrm{E}+02$ & $3.89 \mathrm{E}+02$ & $1.55 \mathrm{E}+05$ & -1.0 & 6.3 & 3.1 & 6.3 & 1.2 & 7.8 & -2.3 & 4.9 \\
\hline FR2_Amont_Chain_7 & $20 \times 20 \mu \mathrm{m}$ & $1.05 \mathrm{E}+01$ & $4.65 \mathrm{E}+00$ & $6.86 \mathrm{E}+03$ & -22.5 & 6.1 & -13.3 & 6.1 & -3.1 & 7.6 & -1.9 & 4.5 \\
\hline FR2_Amont_Chain_8 & $20 \times 20 \mu \mathrm{m}$ & $2.94 \mathrm{E}+00$ & $1.40 \mathrm{E}+00$ & $3.19 \mathrm{E}+03$ & -31.3 & 6.8 & -18.6 & 6.8 & 1.0 & 8.3 & 9.7 & 5.7 \\
\hline FR2_Amont_Chain_9 & $20 \times 20 \mu \mathrm{m}$ & $1.30 \mathrm{E}+01$ & $7.49 \mathrm{E}+00$ & $7.03 \mathrm{E}+03$ & -14.5 & 6.1 & -8.8 & 6.1 & 0.7 & 7.5 & -4.4 & 4.5 \\
\hline \multicolumn{13}{|l|}{ \#5 Downstream Wafer } \\
\hline Cross Section FR5_Aval grain & $3 \times 3 \mu \mathrm{m}$ & $8.24 \mathrm{E}+00$ & $5.49 \mathrm{E}+00$ & $1.24 \mathrm{E}+04$ & -192 & 95 & -214 & 141 & -221 & 98 & -250 & 103 \\
\hline Cross Section FR5_Aval grain & $3 \times 3 \mu \mathrm{m}$ & $4.19 \mathrm{E}+00$ & $1.47 \mathrm{E}+00$ & $9.62 \mathrm{E}+03$ & -144 & 28 & -157 & 50 & -156 & 33 & -147 & 40 \\
\hline Cross Section FR5_Aval grain & $3 \times 3 \mu \mathrm{m}$ & $4.16 \mathrm{E}+00$ & $7.80 \mathrm{E}-01$ & $7.24 \mathrm{E}+03$ & -92 & 16 & -67 & 12 & -62 & 16 & -33 & 15 \\
\hline Cross Section FR5_Aval grain & $3 \times 3 \mu \mathrm{m}$ & $3.32 \mathrm{E}+00$ & $7.40 \mathrm{E}-01$ & $5.07 \mathrm{E}+03$ & 111 & 17 & 133 & 12 & 136 & 14 & 168 & 15 \\
\hline Cross Section FR5_Aval grain & $3 \times 3 \mu \mathrm{m}$ & $1.90 \mathrm{E}+00$ & $9.10 \mathrm{E}-01$ & $2.71 \mathrm{E}+03$ & 244 & 52 & 345 & 31 & 324 & 36 & 367 & 50 \\
\hline Cross Section FR5_Aval grain & $3 \times 3 \mu \mathrm{m}$ & $6.50 \mathrm{E}-01$ & $2.59 \mathrm{E}+00$ & $8.32 \mathrm{E}+02$ & 1241 & 286 & 1284 & 309 & 1181 & 352 & 1204 & 360 \\
\hline
\end{tabular}

\section{Enlargement of the Figure 2.}




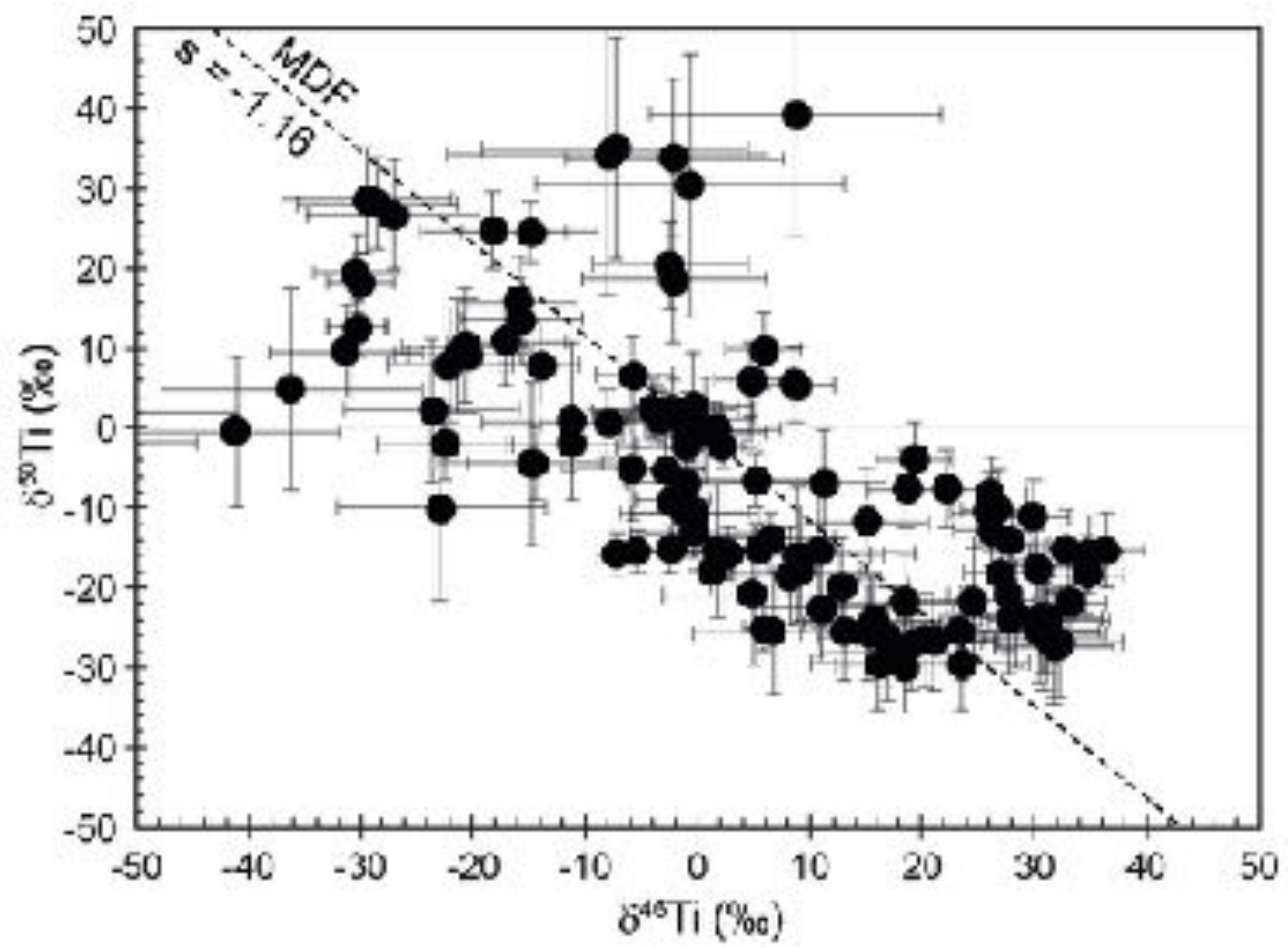

Supplementary Fig.4: A blow-up of the Figure 2 reported in the text, is shown from the data reported in the Table 1 in Methods. The mass-dependent fractionation is observed for small variations in $\delta^{46} \mathrm{Ti}$ vs $\delta^{50} \mathrm{Ti}$. The slope of the mass dependent pattern is calculated for $\bar{\eta}=1$ via the procedure described in Methods (MIF Model). Error bars combine statistical errors (ion counting statistic) and the reproducibility on the standard.

\section{Possible origin for the MIF}

Consider the present experiment where $\mathrm{TiCl}_{4}$ is dissociated by electron impact giving an atom of $\mathrm{Ti}$. As in most photochemical reactions, this atom reacts with its parent molecule. Suppose that, in addition to a chemical reaction with $\left[\mathrm{Cl}_{2}{ }^{i} \mathrm{Ti} . . . \mathrm{TiCl}_{2}\right]^{*}$, an isotopic exchange takes place between $\mathrm{Ti}$ and $\mathrm{TiCl}_{4}$ :

$$
\begin{aligned}
{ }^{\mathrm{i}} \mathrm{TiCl}_{4}+\mathrm{j} \mathrm{Ti} & \rightarrow\left[\mathrm{Cl}_{2}{ }^{\mathrm{i}} \mathrm{Ti} \ldots \mathrm{TiCl}_{2}\right]^{*} \rightarrow{ }^{\mathrm{j}} \mathrm{TiCl}_{4}+{ }^{\mathrm{i}} \mathrm{Ti} \\
\text { or } & \rightarrow\left[\mathrm{Cl}_{2}{ }^{\mathrm{i}} \mathrm{Ti} \ldots . . \mathrm{TiCl}_{2}\right]^{*}+\mathrm{CH}_{2}{ }^{\mathrm{i}, \mathrm{j}} \mathrm{Ti}^{\mathrm{C}} \mathrm{CH}_{\mathrm{x}}+\ldots
\end{aligned}
$$

Hereafter, $\left[\mathrm{Cl}_{2}{ }^{i} \mathrm{Ti} . . . \mathrm{TiCl}_{2}\right]^{*}$ is designated as the "metastable molecule". Using the formalism developed in the framework of the interpretation of MIF in ozone ${ }^{6}$, it is possible to estimate the range of $\eta$ values. We now develop this point.

We define $P r$ and $P n r$ (r and $n r$ standing for reactive (isotope exchange) and non-reactive, (no exchange), respectively) the probabilities that an isotopic exchange takes place (or not) in a given domain of lifetime $\Delta \tau$. During $\Delta \tau$ the metastable molecule spontaneously dissociates 
(reaction 1). In the domain $\Delta \tau$, the relative isotopic abundances of the metastable molecule are proportional to $Y r \cdot P r$ and $Y n r . P n r$ with $Y$ the relative proportion of reactive and non-reactive reactions involved in the formation of the overall metastable molecule (reactions $1+2 ; \mathrm{Yr}+$ Ynr = 1).

When isotopes are distinguishable $(\mathrm{j} \neq \mathrm{i})$, the mean lifetime $\bar{\tau}$ of $\left[\mathrm{Cl}_{2}{ }^{\mathrm{i}} \mathrm{Ti} \ldots \mathrm{TiCl}_{2}\right]^{*}$ is equal to the average lifetime of isotope exchange and non-exchange reactions:

$$
\bar{\tau}(\Delta \tau)=\left[\bar{\tau}_{R(\Delta \tau) . Y r \cdot P r / D}+\bar{\tau}_{N R(\Delta \tau) . Y n r . P n r / D]}=\left[\bar{\tau}_{R(\Delta \tau) . x_{R}}+\bar{\tau}_{\left.N R(\Delta \tau) .\left(1-x_{R}\right)\right]}\right.\right.
$$

with $\bar{\tau}_{R}(\Delta \tau)$ and $\bar{\tau}_{N R}(\Delta \tau)$ the average lifetimes of the metastable molecules yielding $x_{R}$ and $x_{N R}$ to be the relative fractions of reactive and non-reactive reactions $\left(x_{R}+x_{N R}=1\right)$ in the domain $\Delta \tau$ (reaction 1) and with:

$$
D=Y r \cdot P r+Y n r \cdot P n r
$$

If isotopes are indistinguishable ( $\mathrm{j} \equiv \mathrm{i}), \operatorname{Pr}$ and $P n r$ must not be split and $P_{I}$ must be used in place of $\operatorname{Pr}$ or $\operatorname{Pnr}$ (I stands for Indistinguishable). PI drops in the lifetime $\bar{\tau}_{\mathrm{I}}$ of $\left[\mathrm{Cl}_{2}{ }^{\mathrm{i}} \mathrm{Ti} \ldots\right.$ $\left.\mathrm{iTiCl}_{2}\right]^{*}$, giving:

$$
\bar{\tau}_{\mathrm{I}}(\Delta \tau)=\left[\bar{\tau}_{R}(\Delta \tau) . Y r+\bar{\tau}_{N R}(\Delta \tau) .(1-Y r)\right]
$$

This result obtained for $\bar{\tau}_{\mathrm{I}}(\Delta \tau)$ illustrates the fact that the reactant atoms Ti can be either in the products of reaction (1) and/or (2). The mass independent isotopic fractionation factor $\eta$ is:

$$
\eta(\Delta \tau)=\bar{\tau}(\Delta \tau) / \bar{\tau}_{\mathrm{I}}(\Delta \tau)
$$

In a given range $\Delta \tau, \eta \neq 1$ and the isotopic compositions of the products of the reactions (1) and (2) are mass independently fractionated relative to the reactants $\mathrm{TiCl}_{4} / \mathrm{Ti}$. If the chemical reaction (2) samples the overall metastable molecules (i.e. in the range $0<\Delta \tau<\infty$ ), the channel (1) is closed, $\eta=1$ and the isotopic fractionation is mass dependent.

The possible variations of $\eta$ with different values of the parameters $\tau_{R}, \tau_{N R}, x_{R}$ and $Y r$ are shown in Supplementary Fig.5. The parameter $\eta$ is essentially governed by the $\tau_{R} / \tau_{\mathrm{NR}}$ ratio: at the reasonable conditions $x r=1, Y r<0.2, \tau_{\mathrm{R}} / \tau_{\mathrm{NR}}>15$ give $\eta \geq 4$ (as observed in this study). Qualitatively, this estimate implies that (i) all the isotopically exchanged Ti atoms $\left(x_{R}=1\right)$ are stabilized via the channel (2); (ii) that these exchange reactions account for less than $20 \%$ of all reactions forming the metastable molecule $(X r<0.2)$ and (iii) that the lifetime of the reactive metastable molecules should be 15 fold the lifetime of the non-reactive's one. The 
point (iii) is an open question that needs to be theoretically evaluated. The point (ii) indicates that most of the reactions do not yield isotope exchange.

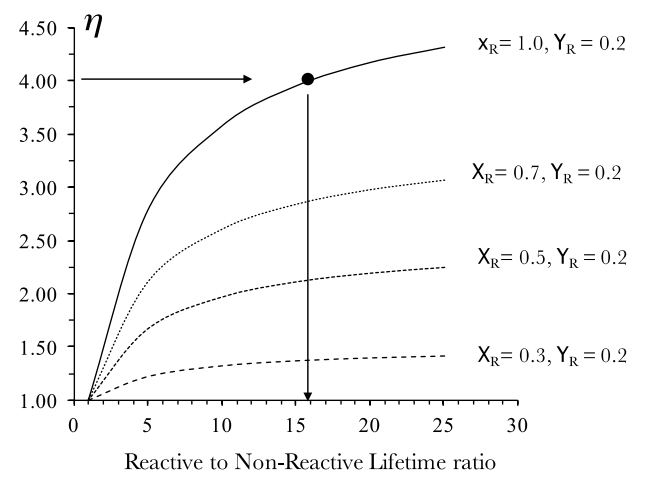

Supplementary Fig.5: A first-order calculation of the variations of the MIF factor $\eta$ with the isotopically exchanged and non-exchanged lifetime ratio of a metastable molecule. The presently inferred value for $\eta$ (black dot on the figure) should correspond to $X r$ and $Y r$ close to 1 and 0.2 , respectively, i.e. to the fractions of isotopically exchanged molecules in the channel (2) and in the channels (1)+(2), respectively. 


\section{Comparison with meteorite data.}

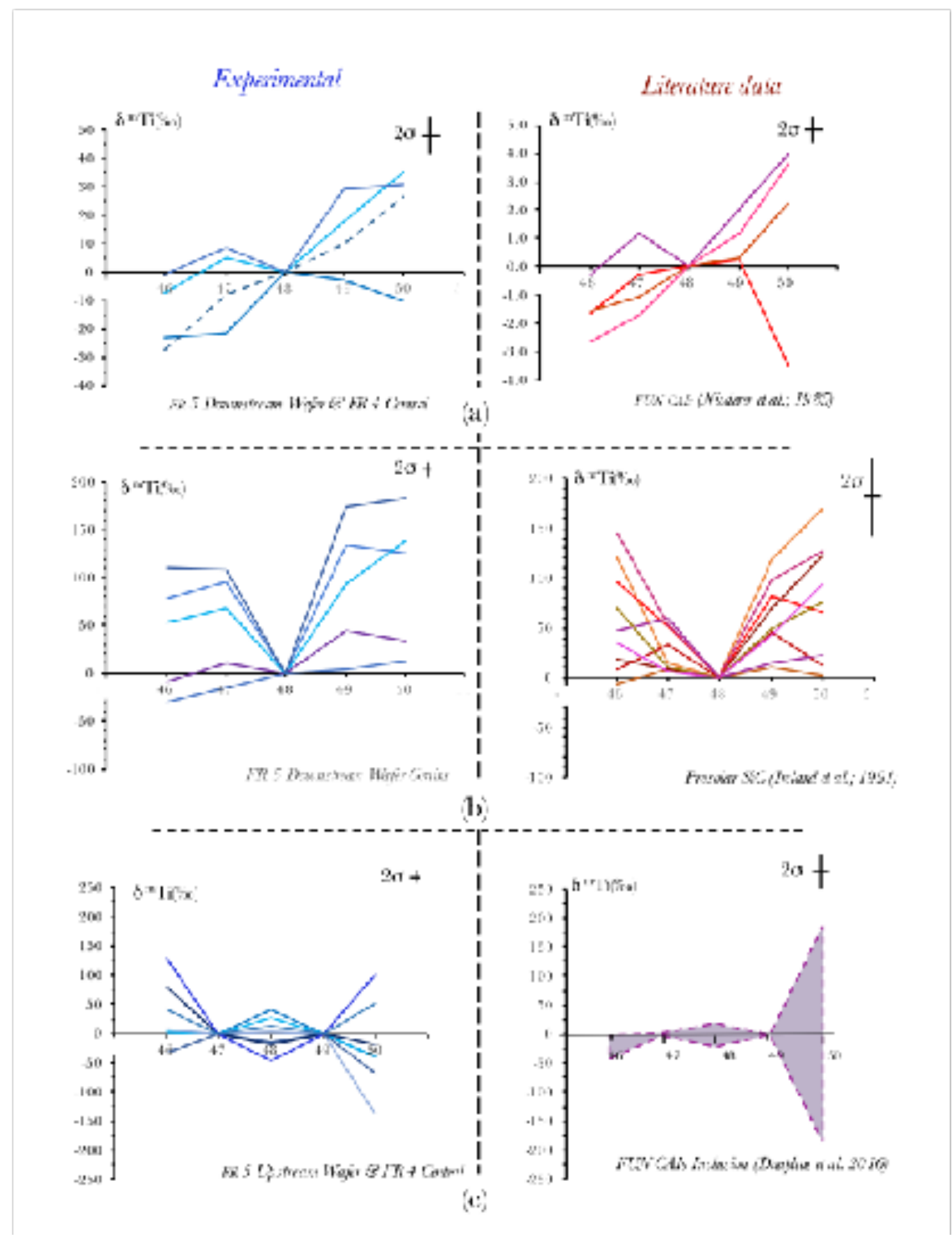

Supplementary Fig.6: Comparison of the Ti isotope compositions of selected experimental samples (blue) with, in red, meteorite components such as FUN CAIs or presolar grains ${ }^{1,8,31}$. Isotopic compositions are expressed with the normalization at mass 48 ( $\mathrm{a}$ and $\mathrm{b}$ ) or with the double normalization at masses 47 and 49 (c).

\section{Supplementary References:}


(31) Niederer, F. R., Papanastassiou, D. A. \& Wasserburg, G. J. Absolute isotopic abundances of Ti in meteorites. Geochim. Cosmochim. Acta. 49.,835-851 (1985). 